\title{
Quantidade, tempo de pressão e padrão de dor referida em pacientes portadores de Dor Miofascial
}

Renato Oliveira Ferreira da Silva

Dissertação apresentada àFaculdade de Odontologia de Bauru, da Universidade de São Paulo, como parte dos requisitos para obtenção do grau de Mestre em Odontologia, área de Reabilitação Oral.

(Edição Revisada) 


\section{Quantidade, tempo de pressão e padrão de dor referida em pacientes portadores de Dor Miofascial}

Renato Oliveira Ferreira da Silva

Dissertação apresentada à Faculdade de Odontologia de Bauru, da Universidade de São Paulo, como parte dos requisitos para obtenção do grau de Mestre em Odontologia, área de Reabilitação Oral.

Orientador: Prof. Dr. Paulo César Rodrigues Conti 


\begin{tabular}{|l|}
\hline da Silva, Renato Oliveira Ferreira \\
Si38q Quantidade, tempo de pressão e padrão de dor referida \\
em pacientes portadores de Dor Miofascial / Renato Oliveira \\
Ferreira da Silva. - Bauru, 2003. \\
107p. : il.; 30cm. \\
Dissertação. (Mestrado) - Faculdade de Odontologia de Bauru. \\
USP. \\
Orientador: Prof. Dr. Paulo César Rodrigues Conti. \\
\end{tabular}

Autorizo, exclusivamente para fins acadêmicos e científicos, a reprodução total ou parcial desta tese, por processos fotocopiadores e outros meios eletrônicos

Assinatura do autor:

Data:

Projeto aprovado pelo Comitê de Etica em Pesquisa da Faculdade de Odontologia de Bauru - USP. Protocolo de pesquisa no 059/2002. 


\section{Renato Oliveira Ferreira da Silva}

$28 / 12 / 1974$

Ilha Solteira - SP

Filiação

1995-1998

1999

$1999-2000$

2001-2003

Associações
Nascimento

Jessé Martins Ferreira da Silva

Eliana Oliveira da Silva

Curso de Graduação em

Odontologia - Faculdade de

Odontologia de Bauru, Universidade de São Paulo.

Treinamento Clínico

Supervisionado no

Departamento de Prótese e Periodontia da Faculdade de Odontologia de Bauru.

Curso de Aperfeiçoamento em Periodontia no Instituto de Ensino Odontológico Bauru.

Curso de Pós Graduação em Odontologia, área de Reabilitação Oral, nível de mestrado, na Faculdade de Odontologia de Bauru.

Associação Paulista de Cirurgiões Dentistas. 


\section{Dedicatória}

"O temor do Senhor é o princípio da sabedoria: os loucos desprezam a sabedoria e a instrução...Porque do Senhor vem à sabedoria : da sua boca o entendimento e o conhecimento...Então entenderás a justiça, e juízo e equidades e todas as boas veredas". Provérbios, 1:7, 2:6,9.

Dedico este trabalho a Deus, pois Ele nos dá a graça da vida e permite que tenhamos sabedoria e discernimento necessários para uma vida em acordo com os princípios cristãos. 
Aos meus pais e professores, Jessé e Eliana por todo o esforço e superação que mostraram na vida, sendo referência de dedicação aos filhos e a docência. Creio que vocês me criaram no caminho da sabedoria, combateram o bom combate e, se um dia eu puder ser e fazer para meus filhos um décimo do que fizeram por mim, sei que estarei feliz, pois conseguirei passar para eles o amor, a paciência e o valor do trabalho.

Muito Obrigado por sempre me apoiarem. Amo vocês.

A todos os meus familiares, avós, tios, tias, primos e primas por nunca duvidarem da minha capacidade.

Aos meus irmãos, Emília e Henrique, pelo suporte e apoio e sacrifício que temos feito para progredir na vida. Vale a pena! 


\section{Paulo César Rodrigues Conti}

Sempre que eu penso em como agradecer o apoio e a confiança em mim depositado por você, não vejo como expressar em palavras meus sentimentos. Espelho de seriedade científica; amor pelo trabalho; paixão pela odontologia, estas são apenas algumas características deste amigo que conquistei com o passar do tempo. Obrigado pela prestatividade, pela paciência e pelo convívio agradável. Minhas reverências e admiração. 


\section{Paulo Martins Ferreira}

Impossivel eu não agradecer a quem nestes oito anos em que estou envolvido com odontologia sempre me apoiou, orientou e ajudou a crescer profissionalmente. Abriu-me portas para não somente o despertar da ciência, mas também da prática clínica, sempre permitindo ser seu parceiro, aluno e amigo. Obrigado sempre pelos conselhos, orientações e puxões de orelha. Por mais que eu tente retribuir, sempre estarei em débito contigo. 


\section{José Henrique Rubo}

Minha admiração é pela paciência que você possui, pelo espírito de equipe que ele formou, não somente comigo, mas com toda a minha turma de mestrado, proporcionando e dividindo conhecimentos que, sem o seu esforço, não seria possível. Sinceramente meu muito obrigado. 
Agradecimentos:

Andrea Gandolfi Berro, pela paciência, dedicação e compreensão neste tempo todo. Você é muito especial.

Rafael dos Santos Silva, por ser grande amigo, colega e responsável por este trabalho. Sem você não seria possivel a realização do mesmo.

Luis Gustavo Cavalcanti Bastos (Lula), simplesmente por ter sido companheiro dentro e fora do curso.

Jefferson Ricardo Pereira, pela amizade, companheirismo e bons momentos que passamos juntos. Valeu Mané!

Paulo Henrique Orlato Rosseti, por ser humilde, parceiro e sempre prestativo.

Aos colegas de Mestrado: Stella, Tatiany, Leylha, Mariana, Luciana, Osvaldo e Mauro. Por todas as experiências que pudemos compartilhar. 
Aos Professores do Departamento de Prótese: Carlos dos Reis Pereira Araújo, Wellington Cardoso Bonachela, Renato de Freitas, Lucimar Falavinha Vieira, Gérson Bonfante, Vinícius Carvalho Porto, Milton Carlos Gonçalves Salvador. Sou muito grato pelo conhecimento e experiência compartilhados.

Em especial a dois professores: Accácio Lins do Valle, pelos ensinamentos e agradável convivência que sempre tivemos. Luis Fernando Pegoraro, pelo empenho, dedicação e ensinamento exemplares a todos os alunos de pós-graduação.

Ao Lauris, ou melhor, Prof. José Roberto Pereira Lauris, pela importante ajuda com a análise estatística e também pela agradável convivência que possuímos.

A três professores que foram e são exemplos de dedicação ao ensino: Ana Lúcia Álvares Capelozza, Luís Alberto de Assis Taveira (Picolé), e Ricardo Marins de Carvalho. 
Aos colegas e amigos sempre: Diego, Leonardo, Celso, Rico (Luís Fernando) e Jordy (Fernando)

Márcia e Marcelo Contador Gallina, pela paciência com meus horários e pela oportunidade de parceria. Obrigado!

Funcionários do Departamento de Prótese: Edna, Débora, Reivanildo, Marcelo, Walquíria, Cláudia, Didi, Geraldo, Luzia.

Pessoal da Pós-Graduação: Dona Ana, Cleusa, Geane, Aurélio. Muito Obrigado!

Colegas do Doutorado: Carlinhos, Rudys, Barnabé, Juliano, Stefânia, Anuar, Gildo, Nelsinho.

Estagiários: Estevam, Samara, Jonas, Lucas, Érico, Mikaela, Thania e Sadam (Valdey) por sempre serem prestativos.

A Dona Leni, pela extrema paciência durante os atendimentos e contratempos que tivemos na execução do tratamento. Obrigado! 
A CAPES pelo apoio financeiro primordial para a realização desta etapa profissional.

A Faculdade de Odontologia de Bauru - USP, na pessoa da sua diretora, Profa. Dra. Maria Fidela de Lima Navarro. Por ser a minha escola, minha casa e minha paixão. Obrigado por tornar possiveis as minhas realizações.

A todos o meu agradecimento 


\section{Sumário}

Lista de Figuras .........................................

Lista de Tabelas............................................ xiii

Lista de Abreviaturas.................................... xiv

Resumo......................................................

1 - Introdução .............................................

2 - Revisão de Literatura...................................

3 - Proposição............................................... 46

4 - Material e Métodos..................................... 49

$5-$ Resultados............................................

6 - Discussão ...............................................

7 - Conclusões............................................... 99

Anexos.....................................................

Referências Bibliográficas.................................. 105

Abstract........................................................ 


\section{Lista de Figuras}

Figura 4.1 - Algômetro Kratos ${ }^{\circledR}$ utilizado no exame de palpação muscular.

Figura 4.2 - Painel de controle do aparelho. Chave 1 regula o registro do maior valor de pressão obtido na palpação. A chave 2 controla a unidade de pressão desejada. A 3 o tipo de força (tração ou pressão). A chave 4 liga e desliga $o$ aparelho.

Figura 4.3 - Ponta circular achatada que entra em contato com a pele do paciente ( diâmetro $=1 \mathrm{~cm})$.

Figura 4.4 - Pressão realizada no corpo de músculo masséter.

Figura 4.5 - Palpação realizada na porção média do músculo temporal.

Figura 4.6 - Palpação do músculo esternocleidomastóideo.

Figura 4.7 - Palpação do músculo trapézio.

Figura 5.1 - Cada ponto em azul representa o tempo de pressão mantido em cada PG, necessário para desencadear o processo de DR. A linha pontilhada representa a média deste tempo. 


\section{Lista de Tabelas}

Tabela 5.1 - Número de pacientes, média de pressão e desvio padrão do grupo A.

Tabela 5.2 - Número de pacientes, média de pressão e desvio padrão do grupo B.

Tabela 5.3 - Média de tempo de palpação em cada músculo.

Tabela 5.4 - Locais de manifestação de DR no músculo masséter.

Tabela 5.5 - Áreas de DR manifestadas pelo músculo temporal.

Tabela 5.6 - regiões de manifestação de DR do esternocleidomastóideo.

Tabela 5.7 - Padrão de DR apresentado pelo músculo trapézio.

Tabela 5.8 - Teste "t" de Student para os grupos estudados.

Tabela 5.9- Teste Anova a 1 critério e Teste de Tukey para o tempo de pressão.

Tabela 6.1 - Média do LDP em pacientes portadores de dor miofascial. 
Tabela 6.2 - Áreas de dor referida segundo Travel ${ }^{\beta 9}$; Travell, Simons ${ }^{42,43,44,45}$, Jaeger ${ }^{15}$; Fricton et al. ${ }^{6}$; Reeh, EIDeeb ${ }^{29}$; Saxen ${ }^{31}$; Wright. ${ }^{47 *}$ Cruzou a linha média. 


\section{Lista de Abreviaturas}

DTM - Disfunção Temporomandibular

PG - Ponto Gatilho

DR - Dor Referida

ATM - Articulação Temporomandibular

LDP - Limiar de Dor àPressão 
Resumo 


\section{$\underline{\text { Resumo }}$}

Os propósitos deste estudo foram: determinar a quantidade de pressão que estimulasse resposta dolorosa em pacientes com sinais e sintomas de dor miofascial quando comparado ao grupo controle assintomático; determinar um intervalo de tempo de manutenção de pressão para que houvesse o surgimento do processo de dor referida (DR) e verificar o padrão de DR provocada pelos pontos gatilho (PG). Para isto foram selecionados 24 pacientes portadores de dor miofascial e para o grupo controle, 20 indivíduos livres de qualquer sintomatologia de disfunção temporomandibular. Ambos os grupos foram examinados por um único examinador em pontos gatilho previamente diagnosticados. Os dados obtidos para a quantidade de pressão foram analisados estatisticamente, sendo adotado um nível de significância de 1\%. Para o quesito quantidade de pressão, 0 intervalo no grupo portador de dor miofascial foi significantemente menor que 0 intervalo do grupo controle. Em relação ao tempo, o intervalo ficou entre 2 e 16 segundos, com média de 7 segundos. O padrão de DR obtido confere com aquele descrito na literatura. Os autores deste estudo concluíram que o limiar de dor a palpação em portadores de dor miofascial é menor que em indivíduos não portadores, o tempo médio necessário para gerar DR é de 7 segundos e o padrão de a manifestação de DR semelhante ao descrito na literatura. 
Introducão 
$\underline{\text { Introdução.doc }}$

\section{1 - Introdução}

As Disfunções Temporomandibulares (DTM) podem acometer uma grande parcela da população e caracterizam-se pela presença de sinais e sintomas nos músculos da mastigação, na articulação temporomandibular ou em ambos. ${ }^{28,31}$

As disfunções miogênicas possuem características próprias como dor muscular à palpação, limitação de movimento, sensação de fraqueza, etc. ${ }^{39}$ Estas alterações podem ser reflexos de alterações não originadas nos músculos ou então de processos realmente originados na musculatura mastigatória e cervical. ${ }^{39,47,48 .}$

Uma das condições que afetam os músculos e que possuem um alto grau de incidência é a dor miofascial. Este processo doloroso tem origem em pontos localizados na musculatura e que devido a fatores locais e sistêmicos, causam tanto dor muscular nestes pontos quanto em estruturas distantes deste ponto. ${ }^{6,7}$ Como o local de sensibilidade no músculodispara o processo de dor à distância, é denominado de Ponto Gatilho (PG). A dor que estes PG causam em outras regiões é denominada Dor Referida (DR). A região de manifestação da DR pode ser outros músculos, dentes, gengivas, articulação temporomandibular (ATM) e ouvidos. $6,7,19,22,26,28$. 
$\underline{\text { Introdução.doc }}$

Apesar de ser um assunto descrito e especificado na literatura médica e odontológica, há muita confusão devido àfalta de achados orgânicos óbvios, sendo que a maioria dos fatores perpetuantes está freqüentemente associado com fatores psicológicos e comportamentais. Somando-se a isto, também não há uma teoria convincente que explique a formação das dores miofasciais. ${ }^{39}$. Devido a estes fatores subjetivos, achados objetivos em relação à quantificação da sensibilidade das estruturas envolvidas na dor miofascial era de difícil e não possuía muito suporte científico até 1986, quando Jensen e col. ${ }^{16 .}$ desenvolveram aparelho denominado algômetro para medir o limiar de dor à pressão (LDP) em pacientes com dor miofascial.

Os estudos que demonstram a aplicação de algômetros para a determinação do LDP mostram que estes aparelhos são fontes confiáveis e os resultados possuem de boa à excelente reprodutibilidade tanto interexaminadores quanto intra-examinadores, sendo assim um instrumento útil para avaliar a condição inicial do paciente e também a evolução do tratamento. ${ }^{15,16,17,24} \mathrm{~A}$ aplicabilidade clínica dos algômetros não se limita somente à avaliação dos pacientes, mas também no treinamento de profissionais e alunos que vão atuar na área de DTM, sendo uma fonte fidedigna de calibração dos indivíduos para a realização dos exames de palpação manual. A necessidade desta calibração é importante, pois muitas variáveis podem interferir na técnica de palpação, como a quantidade de força aplicada com os dedos, variando de examinador para examinador. ${ }^{15,16,17,24,2729}$ 
$\underline{\text { Introdução.doc }}$

O padrão de dor referida para a região de cabeça e pescoço foi estabelecido primeiramente por Travell em $1960^{38}$ e, posteriormente, por outros autores como Fricton e col. ${ }^{6}$ e Wrigth ${ }^{48}$. Os PG presentes nos músculos quando estimulados produzem DR, sendo que o local de manifestação desta dor segue um padrão comum para os pacientes, e normalmente à distância do PG responsável pelo fenômeno.

A presença da DR não deve ser negligenciada, pois pode levar a um diagnóstico incorreto, o que causa, muitas vezes, uma abordagem terapêutica executada de maneira incorreta. 7,19,22 Traumas psicológicos e cronificação do processo podem ser as conseqüências deste fato. Mutilações como exodontias, extirpações pulpares, confecções de próteses ou cirurgias ortognáticas, causam além do dano físico ao paciente, também financeiro e perda de tempo. ${ }^{26,28,31}$

Devido a estes fatores, é de extrema importância que o profissional esteja hábil a identificar estas áreas de DR, os PG, bem como características de quantidade de pressão a ser aplicada nos PG, tempo de pressão necessário para o surgimento da DR, assim como também o local de mais comum manifestação de DR provocada pela estimulação dos PG. ${ }^{1,6,7,47}$ 
Revisão de Literatura 


\section{2 - Revisão de Literatura}

Alguns dos problemas que podem existir e confundir a pessoa que se propõe a estudar as dores miofasciais é o fato de haver na literatura vários termos diferentes que descrevem a Síndrome da Dor Miofascial. Outro fato que não se pode deixar de elucidar é que há na literatura uma série de condições médicas diferentes, com origens e causas distintas que produzem padrões similares de dor muscular. ${ }^{24,42}$

Froriep $^{24}$ foi um dos autores que no século retrasado utilizou diversos nomes para descrever pontos extremamente sensíveis e duros cujo tratamento efetivo causou alívio da dor muscular. Adler ${ }^{24}$ descreveu a alteração como reumatismo muscular, porém, Gowers e Stockman ${ }^{24}$ nomearam as alterações de fibrosite. Através dos tempos, vários termos foram sendo utilizados, em alemão ou em inglês, para designar as alterações miofasciais. $^{24}$

A partir da década de 30 do século passado, três autores publicaram estudos no qual eles descreviam as características dos PG, porém sem nomearem como PG. A tríade é composta por Michael Gutenstein ${ }^{24}$, que publicava seus estudos com o pseudônimo de Good; Michael Kelly ${ }^{24}$ e Janet Travell $^{24}$. Segundo Mense e Simons ${ }^{24}$, somente os conceitos de Travell tiveram influência com o passar do tempo. 
Keele, no ano de $1954,{ }^{18}$ afirmou existir a necessidade de, durante o exame para a obtenção de o LDP, o paciente estar relaxado e tranqüilo. O mesmo não deve se sentir intimidado pelo procedimento ou por algum tipo de aparelho utilizado. Um outro fator que o autor afirmou ser importante é a taxa de pressão aplicada sobre o local palpado. Esta deve ser constante, o que evita a fadiga tanto do examinador quanto do local examinado, sendo a taxa ideal de palpação $1 \mathrm{~kg}$ por segundo. Ele determinou através de uma amostra de 260 pessoas uma classificação com as seguintes categorias: hipersensíveis (sensibilidade até $1,5 \mathrm{Kg}$ ), normo-sensíveis (sensibilidade entre 2,0 e 4,0 kg) e hiposensíveis (força aplicada acima de 4,0 Kg). A conclusão obtida foi que a maior deficiência na utilização da pressão digital é o fato que não se pode mensurar a força aplicada. O problema seria solucionado por meio da utilização do algômetro.

Travel$^{38}$, em 1960, publicou um dos primeiros artigos onde foi descrito o padrão de dor referida em pacientes portadores de dor miofascial na região de cabeça e pescoço. Observou que o tecido muscular, quando é submetido a estímulos nocivos de origem mecânica, metabólica, emocional, infecciosa, nutricional ou uma combinação de todos estes, reage, apresentando espasmos e encurtamento. Os músculos no estado de espasmo perdem a capacidade de relaxamento voluntário. Exibem também um estado de super contração ou resistência ao alongamento.

Ainda observou outros problemas que afetam este tipo de paciente: dor associada ao espasmo muscular e dor referida à distância da região que 
seria a fonte de dor. Esta dor à distância dependeria de uma pequena zona de hipersensibilidade, conhecida como ponto gatilho, localizado no músculo ou na fáscia, e altamente sensível ao estimulo por pressão. Esta área, quando estimulada por pressão ou pela inserção de uma agulha, desencadearia a dor à distância. Quando se injeta va uma solução anestésica o processo de DR era eliminado. A dor causada pelo encurtamento muscular pode permanecer como um processo patofisiológico por longos períodos, porém possui imediata reversibilidade. Em questão de poucos minutos, procedimentos executados na área do ponto gatilho podem extinguir a contração muscular, restabelecendo assim o comprimento e função normal deste músculo, mesmo que este tenha ficado num estado de limitação de movimento e dor por um longo período, como meses ou anos. Somente uma desordem patofisiológica pode ser imediatamente e permanentemente encerrada com procedimentos que possuem efeitos farmacológicos transitórios, como infiltração com anestésico ou "spray" de cloreto de etila. A biópsia das áreas do ponto gatilho não se distingue em nada de áreas normais na musculatura.

Travell ${ }^{38}$ ainda descreve u o padrão de dor referida de cada músculo, sendo que cada parte do tecido muscular tem um padrão específico de dor referida, ou seja, ponto gatilho localizado em uma determinada área muscular refere dor sempre para o mesmo local. Este padrão de dor referida não segue necessariamente uma distribuição neurosegmental simples, sendo que sua constância depende de caminhos anatômicos fixos que ligam os pontos gatilhos às áreas de dor referida. 
Através do agulhamento dos pontos gatilho, Travel| ${ }^{38}$ conseguiu mapear as áreas de dor referida. Quando a agulha era inserida no músculo normal, nenhum tipo de dor referida foi produzida, porém quando injetada solução salina neste, desencadeava dor referida transitória. Este procedimento foi utilizado para auxiliar no mapeamento da dor referida. $\mathrm{O}$ padrão de dor referida era similar em ambos os métodos (injeção salina e palpação ou injeção nos $P G)$, porém processo de dor referida induzido por injeção de solução salina no músculo normal, não informou onde comumente se desenvolveu o ponto gatilho na musculatura. ${ }^{38}$

Para cada músculo foi feito um mapeamento do padrão de dor referida. Para o músculo masséter, quando os pontos gatilho estão na porção superficial do mesmo, as áreas de dor referida são principalmente os maxilares, molares e gengivas. Da borda anterior e parte superior do masséter superficial, a área de DR é os molares superiores. Quando a área do ponto gatilho é a inferior, a área de DR é a região dos molares inferiores. No ângulo da mandíbula a área é em volta do olho, subindo em arco através da face. Para o feixe profundo do mesmo músculo, a dor referida é principalmente para a articulação temporomandibular (ATM) e dentro do ouvido. Quando houve a injeção salina na porção do músculo que está sobre o ângulo da mandíbula, a dor referida era quase que totalmente sentida como sendo dor de dente na maxila, sendo também percebida na ATM e no meato acústico externo.

Para o músculo temporal, dependendo do feixe muscular, temos uma área em que pode ser desencadeado o processo de DR. No feixe anterior, a 
área de dor referida pode ser sentida para frente sobre a crista supra-orbital e inferiormente nos incisivos superiores. Já no feixe posterior, a dor pode ser sentida nos molares superiores e região occipital e, no feixe médio, a dor pode migrar para os dentes, têmpora e menos freqüentemente para a ATM.

O músculo pterigóideo lateral pode desencadear o processo para a ATM e maxila. Para os dentes, não foi observado o processo de dor referida. Segundo Travell ${ }^{38,}$ é o principal causador de dor na ATM.

Para o músculo pterigóideo medial, os PG produzem dor em estruturas dentro da boca, como língua, palato duro e a própria ATM.

A estimulação dos pontos gatilho pode levar não somente ao aparecimento de dor, mas também gerar sensibilidade àpressão em estruturas profundas e sensibilidade ao calor e frio. Salivação e lacrimejação do mesmo lado do ponto gatilho podem ser um achado.

No músculo trapézio a dor referida pode ser sentida no ângulo da mandíbula, aspecto postero-lateral do pescoço e processo mastóide, têmpora, fundo de olho, molares inferiores e occipital.

O músculo esternocleidomastóideo pode desencadear o processo na região frontal, crista supra-orbital, ouvido médio e região posterior auricular, dor difusa na bochecha e raramente nos molares. Pode também eventualmente cruzar a linha média e causar dor referida na região frontal. Quando o ponto gatilho está localizado na origem externa do músculo, a dor pode caminhar para baixo em direção ao esterno. 
Travell ${ }^{38}$ ainda descreveu como estas desordens musculares com dor referida podem aparecer, podendo ser repentina quando acontece algum episódio de trauma, como força em demasia para morder algum objeto, consultas odontológicas demoradas, estresse da musculatura mastigatória. O aparecimento gradual pode ser caracterizado pelo surgimento de problemas articulares e subseqüente surgimento de dor e limitação de movimento ou vice-versa, e a má postura pode ser o principal fator desencadeante conjuntamente com falta de equilíbrio oclusal e assimetria de face. Outras duas hipóteses a serem investigadas são a presença de algum tipo de infecção, que pode causar o espasmo muscular, como infecção oral, respiratória ou estresse emocional.

Após todo o estudo, a autora concluiu que os pontos gatilho localizados na musculatura facial e do pescoço referem dor para determinadas áreas, assim como algumas manifestações não dolorosas, como salivação, lacrimejamento, coriza, e outro. Os dentes também servem como zona dor referida, podendo ter uma hipersensibilidade à pressão, frio, calor e dor sem nenhum motivo aparente.

Travell e Simons ${ }^{39}$ relataram que as mulheres são mais propensas à dor miofascial e a literatura também reporta que mais mulheres do que homens procuram ajuda específica para tratamento deste quadro doloroso. Descrevem alguns sintomas específicos que estão relacionados com os PG:

1. Dor miofascial é referida de PG em padrões específicos e característicos de cada músculo. 
2. Os PG são ativados diretamente por uma sobrecarga repentina, fadiga, trauma direto e resfriamento.

3. Os PG são ativados indiretamente por outros $P G$, doenças viscerais, articulações com processo de artrite e estresse emocional.

4. $\quad$ PG ativos variam em irritabilidade de hora em hora e dia em dia.

5. Um PG latente pode ser transformado em ativo por diversos fatores.

6. PG podem causar outros sintomas além da dor.

Ainda descreve m alguns achados clínicos como: Quando há a presença de PG ativos, alongamento passivo ou ativo do músculo aumenta a dor. A amplitude de movimento fica diminuída, sendo que há um a umento da dor quando o músculo afetado é obrigado a se contrair contra resistência. A força de contração máxima deste músculo é diminuída. Existe sensibilidade profunda e diestesia na região de dor referida; o músculo na região circundante ao PG está rígido a palpação; a pressão digital diretamente aplicada ao PG freqüentemente é seguida por um sinal de pulo, que é caracterizado por um movimento brusco por parte do paciente. Os autores descrevem que a pressão firme e moderada no PG intensifica ou causa DR em uma determinada região.

Em relação aos achados laboratoriais, Travell e Simons ${ }^{39}$ relata ram não haver achados que diferenciem as regiões que os PG estão localizados nos músculos de um tecido muscular normal, com alguma exceção na 
atividade eletromiográfica que pode se apresentar, em alguns casos, ligeiramente aumentada.

Ainda em 1983, Travell e Simons ${ }^{40}$ afirmaram, em relação a DR, que a mesma é reprodutível e previsível, e este padrão pode ajudar o clínico na localização e diagnóstico dos PG desde que este a área de DR seja registrada com detalhe e precisamente. Ressaltaram também que o conhecimento anatômico dos músculos é de fundamental importância, pois assim fica mais fácil localizar o PG para realizar a palpação. Este conhecimento anatômico deve ser acompanhado por um conhecimento funcional do músculo, pois a ativação do PG pode ser feita quando o paciente executa determinado movimento. Este fato ajuda no diagnóstico e no entendimento do paciente quando da instrução terapêutica,como, por exemplo, quais os movimentos que o paciente deve evitar executar.

Travell e Simons ${ }^{41}, 1983$, afirmaram que alguns fatores podem atuar como perpetuantes, complicando o tratamento e o alívio dos sintomas da dor miofascial. Os fatores podem ser mecânicos, como assimetrias e desproporções musculares, postura incorreta, abuso dos músculos, prolongada imobilidade podem atuar como agravantes e perpetuar a condição da dor miofascial. Deficiências nutricionais, deficiências metabólicas e endócrinas, fatores psicológicos, infecção crônica também atuam como fatores perpetuantes da dor miofascial.

Travell e Simons ${ }^{42}$ em 1983, descreveram áreas de DR provocada pelos músculos da cabeça e pescoço. Também teceram comentários à 
sobre o envolvimento histórico dos profissionais de odontologia nos estudo e tratamento das dores miofasciais.

Como cada músculo apresenta possíveis áreas de manifestação da DR, para facilitar a leitura e o entendimento, pode-se tratar cada músculo separadamente, o que foi feito pelos pesquisadores Janet Travell e David Simons em 1983, ${ }^{43,44}$ quando comentaram e descreveram cada grupo separadamente. Para o músculo trapézio, normalmente os PG presentes na porção superior do músculo, referem dor para a região do pescoço, atrás da orelha e também para a têmpora. Na região inferior do mesmo músculo, a DR geralmente caminha para o pescoço, região supra-escapular e interescapular. O exame deste músculo é feito através do pinçamento do músculo com o polegar e o indicador, podendo também ser feito o exame aplicando pressão com a ponta do dedo, principalmente nas regiões do trapézio inferior e médio. ${ }^{43} \mathrm{O}$ músculo esternocleidomastóideo possui duas divisões que podem apresentar dor referida em locais diferentes. A divisão esternal provoca DR para a região occipital, através da bochecha, acima do olho, garganta e esterno. A porção clavicular pode gerar dor de cabeça na região frontal e dor no ouvido. A dor gerada na região frontal pode cruzar a linha média, causando dor frontal no lado contralateral do músculo esternocleidomastóideo. ${ }^{44}$

O músculo masséter apresenta de DR na sobrancelha, maxila, mandíbula, nos molares, tanto superiores quanto inferiores, podendo este dentes apresentar mudanças de sensibilidade à temperatura e pressão. $A$ porção profunda do músculo pode referir dor para o ouvido e ATM. O exame 
de palpação é realizado com pressão de um dedo contra a mandíbula. ${ }^{45}$ Por fim, o músculo temporal também pode apresentar DR através do próprio músculo, sobrancelha, dentes superiores, maxila e ATM. Semelhantemente ao músculo masséter, a pressão executada no exame de palpação é feita com a ponta do dedo, pressionando a massa muscular contra o osso temporal. $^{46}$

Fricton e col. ${ }^{6}$, em 1985, analisaram 164 pacientes portadores de dor miofascial. Definiram a Síndrome da Dor Miofascial como sendo uma desordem dolorosa envolvendo dor referida de pontos gatilhos para estruturas miofasciais, no mesmo local ou à distância. O ponto gatilho pode ser definido como uma área sensível no ligamento, tendão ou músculo. Segundo estes autores o surgimento destes pontos gatilho pode ser explicado por dois conceitos.

O primeiro conceito é que há um trauma direto na musculatura e por algum fator, ou por repetitivos microtraumas de alguns hábitos, produzem tensão muscular. O mais freqüente destes fatores é um incorreto hábito postural ou hábitos parafuncionais orais.

O segundo conceito seria ligado a fatores que enfraquecem a musculatura e predispõem a mesma a desenvolverem os pontos gatilhos, como distúrbios nutricionais; desarmonias estruturais; falta de exercícios; distúrbios de sono ou presença de outras desordens; como as desordens de ATM. Como critério de diagnóstico para a amostra utilizada os autores seguiram três pontos, descritos a seguir: 
1. Presença de pontos gatilho:;

2. Queixa de dor que segue os padrões de dor referida causada pelos pontos gatilhos;

3. Alteração reprodutível de dor causada pela palpação direta dos pontos gatilho ativos.

Foi definido o que são pontos gatilho ativos e latentes. Os ativos são os pontos hipersensíveis que ao serem palpados causam dor referida e pontos latentes são aqueles que somente são hipersensíveis, podendo ou não causar DR.

A palpação foi realizada com pressão exercida pela falange distal do dedo indicador deslizando pelo músculo até a área sensível. A alteração de sensibilidade da área é visível e ocorre imediatamente ou em segundos. Ao localizar o ponto gatilho, um sinal de pulo manifestado pelo paciente foi freqüentemente notado, podendo manifestar com a retirada da face, expressão de dor na face e testa ou também através de resposta verbal como "Aî", "Dói aí". Os autores também observaram e registraram o diâmetro dos pontos gatilho encontrados nos músculos do pescoço e da face, sendo que o mesmo variou entre 2 e $5 \mathrm{~mm}$.

Jaeger e Reeves ${ }^{15}$, em 1986, avaliaram as mudanças de sensibilidade nos pontos gatilho com um algômetro após alongamento passivo. Segundo os autores, vários estudos demonstraram que houve uma redução na sensibilidade dos pontos gatilho, sendo que os exames de palpação muscular nestes estudos foram executados utilizando-se a pressão 
digital, sendo impossível medir a quantidade de força exercida. Logo, esta avaliação passa a ser muito subjetiva. Surgiu, então, a necessidade de se utilizar um aparelho como um algômetro para avaliar objetivamente a pressão exercida nos pontos gatilho. Os pacientes foram examinados duas vezes. A primeira antes de iniciar o tratamento e a segunda imediatamente após o tratamento. No estudo 1, a média de pressão exercida nos pontos gatilho antes do tratamento foi de $2.4 \mathrm{Kg}$ e para o grupo pós-tratamento a média foi de $4.1 \mathrm{Kg}$. No segundo estudo, a média antes do tratamento para o lado tratado foi de $2.8 \mathrm{Kg}$. e para o lado não tratado foi de $2.7 \mathrm{Kg}$. Após o tratamento, a média encontrada para o lado que recebeu tratamento foi de $3.8 \mathrm{Kg}$, enquanto para o lado não tratado foi de $2.9 \mathrm{Kg}$.

Reeves, Jaeger e Graff-Radford ${ }^{29}$ em 1986 investigaram a confiabilidade do algômetro na avaliação da sensibilidade dos PG e se propuseram a avaliar três condições. A primeira foi testar a confiabilidade intra e inter-examinador da utilização de um algômetro em PG previamente identificados. A segunda foi testar a confiabilidade inter-examinador em PG não identificados e a terceira, verificar se os PG representam uma área discreta dentro de cada músculo. Como resultados, os autores obtiveram uma alta confiabilidade entre os examinadores, tanto na localização dos PG quanto no LDP dos mesmos. A segunda condição demonstrou confiabilidade significante entre os examinadores na localização dos PG e medida do LDP. Por fim, na terceira concluiu-se que os PG são pontos discretos de sensibilidade dentro do músculo. Como conclusão geral, os autores afirmaram que a habilidade de quantificar e medir confiavelmente a 
sensibilidade dos PG "abre portas" pra um arsenal de possibilidades clínicas e de pesquisa no que diz respeito a problemas miofasciais e dores associadas.

Jensen, Andersen e Olesen ${ }^{16}$, em 1986, desenvolveram um novo tipo de algômetro que possuía uma ponta ativa com uma área equivalente a 0.5 $\mathrm{cm}^{2}$, sendo esta área menor do que a área correspondente àpolpa do dedo indicador. Os resultados de LDP obtidos não podem ser atribuídos somente aos tecidos miofasciais, mas também pelos tecidos cutâneos e subcutâneos, pois com a analgesia destes, aumentou em 70\% o LDP. Porém, na região temporal, os tecidos miofasciais são mais importantes na determinação do LDP do que os tecidos superficiais.

No ano de 1987, Fisher ${ }^{5}$ desenvolveu um estudo no qual utilizou o LDP para o diagnóstico de dor miofascial e avaliação do resultado obtido após tratamento. Definiu que LDP é a pressão mínima exercida que causa dor ou desconforto. Em relação ao algômetro ele ponderou que os algômetros utilizados por Keele; Merkey e Merkey e Spear não eram adequados, pois possuíam uma ponta de madeira com $0.5 \mathrm{~mm}$ de diâmetro, equivalente a $0.196 \mathrm{~cm}^{2}$, o que segundo o autor não provê uma correta transmissão da pressão para as estruturas mais profundas. Determinou que a superfície ideal da ponta ativa do algômetro para a correta transmissão das forças para as estruturas mais profundas seria de $1 \mathrm{~cm}^{2}$, o que corresponde a $1.12 \mathrm{~cm}$ de diâmetro.

Para o exame, pedia-se ao paciente que indicasse a área de maior dor com um dedo e o examinador palpava a área com um dedo para 
identificar o ponto máximo de sensibilidade. Em alguns pacientes a dor foi demonstrada através do sinal de pulo. A maior causa de falhas no exame era achar exatamente o ponto exato de dor máxima, sendo que ao desviarse destes pontos, mesmo que seja apenas algum milímetro, resulta em uma falsa leitura, pois aumenta a pressão necessária.

Em 1989, Langemark e col. ${ }^{20}$ avaliaram o LDP e sensibilidade térmica em pacientes com dor de cabeça tensional crônica. Os pacientes foram examinados por uma mesma pessoa em todas as visitas. Com um algômetro com uma ponta de $0.5 \mathrm{~cm}^{2}$, sendo a aérea palpada e avaliada foi sempre em um mesmo ponto do músculo temporal, de acordo com o que foi descrito por Jensen. Afirmaram ainda que os pacientes portadores de dor miofascial possuem uma LDP menor que os pacientes que não eram portadores ou então pessoas assintomáticas.

Fricton $^{7}$, em 1990, afirmou que a dor miofascial é uma desordem muscular que envolve DR por PG, e estes podem estar próximos ou não do local em que se manifesta o processo doloroso. Este processo pode entrar em um círculo vicioso, o qual é perpetuado por falta de tratamento adequado, manutenção da tensão muscular, postura incorreta e sono não adequado. Afirmou ainda que a origem e processo de ativação dos PG não são bem compreendidas, pois os exames não conseguem detectar mudanças, tanto histológicas quanto bioquímicas, que possam acarretar alguma alteração que elucide ou pelo menos tente elucidar o processo de formação do PG e de DR. 
Reeh; El-Deeb ${ }^{28}$, no ano de 1991, escreveram sobre dor originada por PG com manifestações em dentes. Discutiram os mecanismos de aparecimento da dor miofascial e de dor referida e ressalta ram a importância do correto diagnóstico, já que as dores referidas aos dentes são indistinguíveis das dores de origem endodôntica. Como outros autores também já ressaltaram, eles destacaram a importância do fator psicológico no desenvolvimento dos pontos gatilho e conseqüente surgimento da dor referida. Pessoas submetidas a um período prolongado de estresse, obsessivo-compulsivas, perfeccionistas, de personalidade forte estão mais propensas a desenvolverem tais problemas e o tratamento deve, também, incluir psicoterapia. Os autores lembram que a pessoa não precisa ter problemas emocionais para desenvolver a dor miofascial. Ressaltaram ainda que, por mais bizarra que possa parecer àdescrição da dor, ela é real. Afirmaram que o tratamento não deve ser somente odontológico. O paciente deve ser encaminhado para um tratamento psicológico, sem que este fato seja ofensivo a ele. Após todas as considerações, os autores relataram um caso envolvendo uma mulher de 17 anos em que houve falha em um correto diagnóstico, o que levou a uma série de tratamentos frustrados.

No ano de 1992, foi desenvolvido um estudo por Jensen e col. ${ }^{17}$ no qual através de palpação manual e através de um algômetro eles avaliaram a sensibilidade e o LDP dos músculos cefálicos na população de um modo geral. O LDP em pacientes portadores de dor miofascial provou ser muito confiável, mas em estudos populacionais comparando a palpação manual e o LDP não haviam sido ainda realizados. 
Delaney e $\mathrm{McKee}^{3}$,em 1993, avaliaram a confiança intra e interexaminadores na determinação do LDP em indivíduos portadores de PG. A determinação do LDP em cada PG é um importante índice clínico da severidade e limitação causada pela alteração e que pode ser útil para a avaliação da evolução do tratamento. Na verdade os autores não utilizaram pacientes portadores de dor miofascial, e sim selecionaram 50 voluntários saudáveis e determinaram os locais de palpação. Um algômetro com uma ponta ativa de $1 \mathrm{~cm}^{2}$ foi utilizado e com uma taxa de aplicação de força de $1 \mathrm{~kg} / \mathrm{seg}$. A conclusão dos autores foi que o algômetro é um instrumento de medida confiável, podendo ser utilizado para determinação da sensibilidade muscular em pacientes portadores de DTM de origem miogênica. 0 acompanhamento da evolução do tratamento é também outra aplicação deste instrumento.

Hoheisel e $\operatorname{col}^{10}$ em 1993, desenvolveram um estudo no qual separaram um neurônio no corno dorsal medular de rato, este responsável por um determinado campo receptivo no músculo bíceps femoralanterior, e mediram a pressão que causava estímulo neste neurônio. Após, injetavam bradicinina em um outro músculo, distante do primeiro. A bradicinina é um potente ativador de fibras nocioceptivas. Após cinco minutos, o neurônio separado podia ser excitado de outros dois campos receptivos, totalmente diferentes e que não havia conexão entre eles antes da injeção. Após quinze minutos, o neurônio separado possuía um limiar de estímulo menor do que o medido antes da injeção. Os autores discutem que pode ser um achado que explique o processo de DR. 
No ano de 1994, Reid, Gracely e Dubner ${ }^{30}$ publicaram um estudo no qual avaliaram a influência do tempo, lado facial e localização nos LDP nas DTM crônicas de origem muscular. Disseram que um dos grandes problemas para o exame e detecção das dores musculares é justamente o fato da palpação ser realizada manualmente, o que implica em uma alta variação inerente à técnica, como a diferença de força aplicada por cada examinador, diferentemente da LDP.

Utilizaram 29 pacientes que constituíram o grupo experimental e 11 indivíduos para o grupo controle. Os pacientes, após exame físico e anamnese, eram classificados como portadores de DTM muscular bilateral e crônica (mais de 3 meses). Pacientes com alterações articulares foram excluídos do estudo. O grupo controle foi composto por indivíduos livres de sinais e sintomas de DTM e que nunca apresentaram tais alterações. Os pacientes e o grupo controle foram então palpados em ambos os lados em um intervalo de duas semanas sempre no mesmo local. A ponta ativa do algômetro era de $0.5 \mathrm{~cm}^{2}$.Os resultados mostraram diferenças estatisticamente significantes no LDP entre o grupo controle e os pacientes em todas as medições. Os valores obtidos entre os LDP variaram entre os músculos palpados, mas não variou entre os lados no mesmo paciente. Não houve variação entre os tempos de palpação, o que mostra uma boa reprodutibilidade dos valores do LDP, tanto em pacientes quanto em indivíduos assintomáticos.

O LDP nos pacientes com dor miofascial após injeção de anestésico em PG foi estudado por McMillan e Blasberg ${ }^{21}$ em 1994. Descreveram que 
variáveis como tamanho da ponta ativa do algômetro, velocidade de aplicação da força e grau de contração muscular, podem interferir na leitura ou medição do LDP. Quando estas variáveis são devidamente controladas, a medição é confiável e possui adequada sensibilidade. Os autores mediram o LDP nos músculos masséter e temporal antes e depois da injeção de anestésico nos músculos. Utilizaram um grupo controle no qual os indivíduos não possuíam qualquer tipo de DTM. Os valores obtidos para o grupo controle foram maiores que os valores obtidos para o grupo experimental, havendo diferenças estatisticamente significantes entre os dois resultados.

Juntamente com colaboradores, em 1994 Bendtsen $^{2}$ descreveram um novo tipo de aparelho capaz de com pressão digital medir a intensidade da força aplicada nos tecidos durante o exame de palpação, a fim de avaliar a sensibilidade dos tecidos. Diferentemente dos algômetros anteriormente citados, desenvolveram um aparelho que ele chamou de palpômetro. Este aparelho consiste em um sensor conectado a um instrumento que registrava a intensidade da força aplicada. O sensor foi fixado no dedo indicador do examinador através de uma fita adesiva. A força aplicada ao sensor foi marcada em um medidor, com uma escala dividida arbitrariamente em unidades (AU), variando de 60 a 200 AU. Um algômetro foi utilizado para converter a unidade AU para força.

Este palpômetro foi testado em várias condições, sendo as variações intra e inter-examinadores parte destas condições. A variação intraexaminadores não foi estatisticamente significante, mas houve variações inter-examinadores. A média de pressão exercida foi de $126 \mathrm{AU}$, 
correspondente a $640 \mathrm{~g}$, variando entre 100 e $1480 \mathrm{~g}$. Apesar dos autores terem demonstrado a validade e a reprodutibilidade da pressão exercida e medida por este palpômetro, eles concluíram que o instrumento deve ser pouco utilizado na clínica diária, mas é extremamente valioso quando utilizado para o treinamento de profissionais e obrigatório em estudos científicos quando estes envolvem mais de um observador.

Stholer ${ }^{35}$ em 1995 diz que a dor miofascial é um achado comum pois $52,9 \%$ dos pacientes que procuraram tratamento em um centro especializado no tratamento de dor, foram diagnosticados como portadores de dor miofascial. A dor de origem muscular é tida como uma dor difusa, profunda e que coexiste com sensibilidade muscular. Dor nos músculos mastigatórios não ocorre necessariamente, somente nos músculos da mastigação. Os músculos do pescoço e ombros também podem estar envolvidos. Devido a esta sensibilidade muscular de músculos não mastigatórios, a dor miofascial mastigatória é parte de um grande grupo de alterações musculares que envolvem a região pericraniana, maxila, mandíbula, ouvido médio e musculatura cervical.

Sessle $^{33}$ em 1995 afirma que na periferia dos tecidos há diversos tipos de órgãos sensoriais ou receptores. Estes podem ser de pequeno diâmetro, aferentes primários de condução lenta e associados com terminações nervosas, podendo ser responsáveis por estímulos dolorosos. Existem também terminações mais complexas geralmente associadas com aferentes primários de largo diâmetro, que conduzem estímulos rapidamente. De uma maneira geral, estes funcionam como 
mecanoceptores. Os tecidos miofasciais e articulares são inervados pelas estruturas descritas acima. As fibras aferentes de pequeno diâmetro do grupo III e IV que inervam os músculos e articulações, respondem aos estímulos causadores de dor em humanos, estes podem ser pressão exacerbada, agentes químicos ou agentes inflamatórios. A isquemia também é um estímulo quando mantida por tempo prolongado e concomitante com contrações musculares. Pode-se observar que os nocioceptores são estimulados por uma grande variedade de agentes algogênicos e sua sensibilidade pode ser aumentada após alguma injúria. Este processo é conhecido como sensitização periférica e pode ser o principal fator na produção da hiperalgesia e, conjuntamente com a sensitização central, pode ser a explicação do porque os tecidos ficarem sensíveis e doloridos após alguma injúria ou doença.

Widmer ${ }^{47}$, em 1995, ponderou que técnicas de palpação extra-orais, tanto para a ATM quanto para os músculos exibem adequada reprodutibilidade. A palpação intra-oral mostra que a reprodutibilidade não é tão adequada quando comparada a extra-oral, porém mostra uma reprodutibilidade aceitável. Os algômetros podem melhorar a fidelidade do exame de palpação devido a alguns fatores como: a constante área em contato com a região a ser palpada, facilidade de controlar a direção e a quantidade de pressão aplicada. Afirmou que a reprodutibilidade do exame de palpação com a utilização do algômetro ficou apenas em níveis aceitáveis. 
Em 1995, segundo Scudds e col. ${ }^{32}$, uma grande quantidade de pacientes pode apresentar pontos gatilho latentes, mesmo em indivíduos assintomáticos. Eles então analisaram a freqüência de sinais referidos em indivíduos assintomáticos sob duas condições. A primeira em músculos não sensíveis e em áreas musculares sensíveis. Em ambas foi utilizado um dolorímetro. O primeiro experimento constituiu de 61 indivíduos saudáveis que foram palpados manualmente no quadrante superior direito a fim de determinar qual seria a área muscular menos sensível à pressão. Após localizada a área, aplicava-se o dolorímetro até que o paciente alcançasse o limiar de dor ou relatasse dor referida ou disestesia. O segundo estudo constituiu de 70 adultos saudáveis que foram palpados da mesma maneira que descrita anteriormente só que em ambos os quadrantes superiores a fim de achar a área mais sensível, então se aplicava o dolorímetro da mesma maneira descrita anteriormente.

Os resultados obtidos no primeiro estudo mostraram que 7 dos 61 indivíduos relataram sinais referidos, sendo a média de tolerância àpressão de $12,7 \mathrm{Kg}$. No segundo estudo, 38 de 70 indivíduos relataram sinais referidos em pelo menos um lado da face, sendo que $17 \%$ apresentaram sinais referidos bilateralmente. A média de tolerância àpalpação foi de 13,3 $\mathrm{Kg}$, sendo que não houve diferenças estatisticamente significantes entre os músculos que produziram dor referida e os que não produziram.

Hong e col. ${ }^{11}$ têm estudado as dores miofaciais e os pontos gatilhos exaustivamente e, em um destes estudos publicado em 1996, eles analisaram o LDP para causar dor referida pela compressão dos pontos 
gatilho e também das áreas adjacentes. Um ponto gatilho caracteriza-se por ser uma área dolorosa ou sensível, em uma banda tensa palpável de fibras musculares esqueléticas, que é mais firme que as fibras adjacentes. Outra característica consiste em um padrão de dor referida específico para cada músculo, tanto espontaneamente quanto gerada por compressão. A terceira característica é o limiar de estiramento reduzido de cada músculo envolvido. Por último, uma resposta de contração rápida e forte local, sendo esta contração temporária das fibras musculares em uma banda tensa em resposta a uma palpação que rompe os PG. O PG pode ser classificado em dois tipos: pontos gatilho ativos e latentes. Os PG ativos são aqueles que causam dor referida espontaneamente ou em resposta a um movimento, enquanto o ponto gatilho latente é um ponto sensível com dor ou desconforto como resposta à compressão.

Segundo Hong e col. ${ }^{11} 1996$, a dor referida está atualmente sendo mais bem diagnosticada na clínica diária e seu mecanismo neurológico tem sido documentado. Até certo ponto, a dor referida pode ser atribuída ao aumento de sensitividade local e amplificação de campos nocioceptivos presentes no músculo que existem, mas estão latentes. As fibras dolorosas aferentes dos nocioceptores musculares no campo receptor exibem sinapses não somente com os neurônios responsáveis primeiramente pelo campo receptor, mas também com neurônios vizinhos, estes que normalmente mediam a nociocepção de outras regiões. Outras comunicações entre neurônios que podem ocorrer para a contribuição do fenômeno da dor referida são as conexões "externas inapropriadas" e que às 
vezes, com uma simples estimulação abaixo do limiar de tolerância, podem ativar estes nocioceptores adormecidos.

A dor referida e as bandas sensíveis são características do PG e determinantes no diagnóstico da Dor Miofascial. Porém nem todos os estudos conseguiram demonstrar um diagnóstico confiável dos PG somente nas características mencionadas acima, mesmo em pacientes examinados por especialistas em dor miofascial, pouca associação ocorreu entre a presença de PG e dor referida. O problema pode residir no fato de que os examinadores não eram apropriadamente treinados para se conseguir uma maior uniformidade nos exames do estudo. Pode-se também achar um baixo coeficiente de confiança que confirmasse a presença de dor referida em PG, mas não foi mencionada a quantidade de pressão exercida para desencadear o processo de dor referida. A quantidade de pressão exercida sobre um ponto gatilho é importante, e pode variar de tempos em tempos, mesmo que seja o mesmo examinador, fato este que pode causar inconsistência no surgimento da dor referida. Hong e col. ${ }^{11}$ utilizaram 24 indivíduos com PG latentes no músculo extensor digital comum (EDC) e o segundo grupo foi composto por 15 indivíduos com PG ativos, na porção média do EDC. Um algômetro como o descrito por Fisher foi utilizado para medir a sensibilidade do PG. Limiar de dor, limiar de dor referida e tolerância àdor foram medidos em três pontos nos músculos EDC dos indivíduos de ambos os grupos. A pressão exercida foi aumentada gradualmente nos PG determinados pelos autores, especialistas em dor miofascial e com treinamento adequado no diagnóstico dos PG. Os pontos, latentes ou ativos, 
foram identificados e marcados e denominados de A. Um segundo ponto distal a $\mathrm{A}$ e a $2 \mathrm{~cm}$ de distância na mesma banda muscular tensa foi chamado de B. Um terceiro ponto $C$ foi marcado entre 1 e $2 \mathrm{~cm}$ distalmente a $B$ sendo $1 \mathrm{~cm}$ lateral a banda tensa. Estes três pontos foram palpados. Os autores observaram que a média de compressão para causar dor referida diretamente nos $P G$ ativos foi de $2,73 \mathrm{Kg}$, enquanto o valor para causar dor no PG foi de 2,46 Kg. Para o ponto B, o valor médio obtido para causar dor no determinado ponto foi de $3,07 \mathrm{Kg}$ e para causar dor referida foi de 3,80 Kg. Para o ponto $\mathrm{C}$, o valor médio para causar dor local foi de $3,71 \mathrm{Kg}$, para causar dor referida foi de 4,61 Kg. Para o grupo latente, quando se palpou os $\mathrm{PG}$ em A, o valor para causar dor local foi de $3,23 \mathrm{Kg}$. Para o ponto $\mathrm{B}$, de $4,42 \mathrm{Kg}$ e para C foi de 3,78 Kg. O valor médio encontrado que causou dor referida foi de 4,79 em A; 4,72 em B e 5,16 em C.

Outro achado interessante foi que em $100 \%$ dos $P G$ ativos palpados produziu dor referida quando palpados em A. Quando foram em B, também houve totalidade na produção de dor referida, enquanto em C houve dor referida em $68 \%$ dos indivíduos. Para o grupo latente, em apenas $46,8 \%$ dos avaliados houve produção de dor referida em A. Em B, 36,2\% e em C, $23,4 \%$.

Gerwing e col. ${ }^{8} 1997$, também se preocuparam com a confiabilidade inter-examinadores que o exame dos pontos gatilhos proporcionam, pois segundo eles, o correto exame requer habilidades e prática no exame dos músculos afetados, somando-se o fato que os PG não foram estabelecidos 
como um sinal clínico em nenhum estudo, a reprodutibilidade e confiabilidade do exame inter-examinadores pode ser comprometida.

Dividiram o estudo em duas fases. Na primeira quatro examinadores experientes tanto no diagnóstico, quanto no tratamento de dor miofascial, avaliaram um total de 42 pacientes. Eles não tiveram qualquer treinamento para padronização do exame físico, apenas uma breve explicação de quais músculos seriam avaliados. A segunda parte do estudo envolveu os mesmos examinadores que avaliaram 10 pacientes. A diferença é que nesta parte os examinadores passaram por um treinamento de 3 horas antes do exame, revendo os principais pontos sobre o exame de palpação. Os resultados foram colhidos e analisados estatisticamente e os pesquisadores chegaram à conclusão de que na primeira parte do estudo não houve concordância entre os examinadores para nenhum dos achados que os PG puderam proporcionar. Na fase seguinte, houve concordância entre os examinadores para a maioria dos achados clínicos que um PG pode proporcionar. Concluíram que os PG são achados clínicos reprodutíveis e confiáveis e que um treinamento adequado do examinador, contribui para um melhor desempenho do profissional que irá realizar o exame.

Isselée e col. ${ }^{13}$ avaliaram, em 1997, a reprodutibilidade em curto prazo do LDP nos músculos temporal e masséter em indivíduos assintomáticos. Analisaram 22 indivíduos livres de dor orofacial onde palparam os músculos masséter e temporal com o algômetro desenvolvido por Jensen. Durante o momento da palpação, o examinador apoiava a mão do lado da face contrário ao exame, para prover estabilidade àcabeça. 
Nenhuma diferença foi encontrada entre os sexos, sendo o temporal mais resistente à compressão do que o masséter em ambos os lados. Entre a primeira e a segunda medida houve um decréscimo do LDP, entre a segunda e terceira medidas, houve um acréscimo no valor do LDP e entre a terceira e quarta medida houve um decréscimo do valor do LDP. Não houve diferenças entre os períodos (manhã ou tarde) e entre os dias.

Em 1997, Okeson ${ }^{26}$ escreveu um artigo sobre dores não odontogênicas. O autor citou que para o clínico obter sucesso no diagnóstico e tratamento das dores orofaciais, ele deve saber reconhecer e diferenciar o local da dor e a fonte da dor. Local da dor é o lugar em que o paciente sente a dor,sendo este local é facilmente identificável. A fonte da dor é o local do corpo que origina a dor, podendo ou não, ser o mesmo local em que o paciente a sente. Quando coincide do local de origem ser o mesmo que o de sensação, este tipo de dor é conhecido como dor primária. Por exemplo, quando alguém corta o dedo, a área que apresenta a lesão no tecido é a fonte de dor e também o local que a pessoa sente o reflexo do corte, ou seja, o processo doloroso. Quando porém a área de sensação dolorosa não coincide com o local de origem da sensação de dor, este tipo é então chamado de DR. Um exemplo clássico é quando o paciente sofre uma isquemia do miocárdio, o paciente pode sentir dor no braço, ombro ou mandíbula. A DR também acontece nos tecidos faciais, podendo ser referida para estrutura dentais. Para a obtenção de sucesso no tratamento da dor, uma regra crucial é que os procedimentos para o alívio da mesma e cura 
dos tecidos sejam direcionados diretamente para a fonte da dor, não ao local em que o processo doloroso se manifesta.

Merril ${ }^{25}, 1997$, afirmou que um entendimento básico dos sistemas nervosos central e periférico são essenciais para um correto entendimento dos mecanismos da dor. As fibras sensoriais são divididas em três tipos: Adelta, nocioceptores C-polimodais e os nocioceptores inativos ou adormecidos, sendo que estas fibras podem ser tanto sem bainha de mielina como envoltas por uma fina camada de mielina. Existem também as fibras A-beta, que são mecanoceptoras. Estas respondem a estímulos mecânicos delicados são de largo diâmetro, condução rápida e mielinizadas, transmitindo apenas estímulos de baixa freqüência, não dolorosos e que são interpretados apenas como um leve toque, não importando a frequência ou intensidade do estímulo. Diferentemente das fibras A-beta, as fibras A-delta são fibras de pequeno diâmetro, mielinizadas, de condução rápida de estímulos e que respondem a estímulos mecânicos agudos e dolorosos. Sua condução de estímulos é em alta freqüência percebida com estímulo doloroso. As fibras nocioceptoras C-polimodais são fibras desmielinizadas, portanto de condução lenta de estímulos dolorosos, que podem ser de origem mecânica, térmica e química. Os nocioceptores inativos são mecanicamente insensíveis e, segundo Merril, foram há pouco tempo descobertos. A ativação destes se dá quando há algum tipo de injúria aos tecidos, ativando estes receptores e abrindo uma nova via nocioceptiva ao sistema nervoso central. 
Goulet e col., 1998, ${ }^{9}$ desenvolveram um estudo no qual analisavam a reprodutibilidade dos métodos de detecção da sensibilidade muscular e articular e também da medida máxima dos movimentos mandibulares do sistema temporomandibular. Os objetivos do estudo eram medir e comparar a fidelidade da palpação manual e da pressão exercida por algômetro nos músculos e articulações, testar a consistência interexaminador de um método de medição dos movimentos mandibulares e investigar os fatores que influenciam o consenso entre a consistência dos examinadores o a fidelidade dos pacientes. Os autores definiram como consistência dos examinadores, a proporção de avaliações iguais quando um quesito era avaliado. Definiu que a fidelidade dos pacientes referia à capacidade de um mesmo indivíduo expressar a presença ou ausência de dor, ou desconforto, sob repetidos exames sob condições controladas. Foram palpados pelos autores diversos músculos da face, sendo que estes músculos foram examinados com o auxílio de um algômetro e de forma manual. A palpação manual induziu um índice de palavras relacionadas a dor maior do que a palpação com auxílio do algômetro. Um dos motivos que pode ter acontecido tal fenômeno é que, apesar dos examinadores terem sido calibrados quanto àpalpação, eles podem não ter conseguido mensurar a quantidade de força necessária para realizar o exame, correndo o risco de palparem com mais força do que o necessário.

Isselée e col. ${ }^{14}$ desenvolveram em 1998 um novo tipo de algômetro e avaliaram a reprodutibilidade do LDP dos músculos mastigatórios em um curto período de tempo. Este algômetro era ativado por um botão, aplicando 
então uma força transmitida às estruturas musculares, através de uma ponta de borracha semi-rígida de $11 \mathrm{~mm}$ de diâmetro. Utilizando 27 indivíduos saudáveis, palpou-se os músculos em quatro sessões. A primeira foi entre 8 e 10 da manhã, a segunda entre 3 e 5 da tarde. Dois dias após a primeira sessão, foram realizadas a terceira e quarta sessões nos mesmos horários definidos previamente. Duas palpações foram realizadas durante uma sessão, com um intervalo de 5 minutos, sendo que a primeira palpação foi significantemente maior que a segunda dentro de uma mesma sessão. Não houve diferenças nos valores entre as sessões que eram de manhã ou à tarde ou então entre os dias. Também não houve diferenças entre os sexos dos indivíduos em relação àquantidade de pressão e xercida.

Hong e Simons ${ }^{12}$ revisaram os mecanismos patofisiológicos e eletrofisiológicos dos PG em 1998. Escreveram que os PG têm sido definidos como sendo um ponto localizável e hiperirritado em uma banda tensa do músculo esquelético. São características dos PG: A compressão destes pontos deve provocar dor local e/ou dor referida similar a que 0 paciente reclamou, podendo agravar o quadro de dor. Uma compressão súbita pode gerar uma contração rápida das fibras ao redor ou dentro de uma banda tensa. A inserção da agulha no local também pode provocar uma resposta semelhante. Restrição da amplitude de movimento e fraqueza muscular devido àdor, porém sem atrofia da estrutura envolvida. Os pacientes podem apresentar vasoconstrição, resposta pilomotora, hipersecreção. Por fim um PG ativo é aquele que produz dor referida 
espontaneamente em resposta ao movimento e que o latente somente apresenta sensibilidade ou desconforto a palpação.

Afirmaram que os estudos realizados em humanos que utilizaram o algômetro demonstram a validade e reprodutibilidade na mensuração da sensibilidade dos PG. Outro fator que eles chamaram a atenção foi que nem sempre a compressão de PG ativos causa a dor referida. Em um estudo feito pelos mesmos autores, a dor referida ocorria em $87,7 \%$ dos pacientes quando se fazia o agulhamento dos PG e, quando era realizada a palpação, em apenas $53,9 \%$ houve dor referida. Isto segundo os pesquisadores, pode requerer uma maior quantidade de pressão nos PG, principalmente quando estes pontos forem menos sensíveis.

$\operatorname{Saxen}^{31}$, em 1998, publicou uma breve revisão do que se consiste a Síndrome da Dor Miofascial. Lembrou que esta síndrome existe devido à presença de PG e que este ponto, não difere em nada do músculo normal quando comparados sob microscopia ótica. Algumas diferenças existem, como alterações bioquímicas específicas, que sugerem uma isquemia ou sensitização das terminações nervosas, podem ser a causa da dor gerada nos PG. O diagnóstico da dor miofascial é feita baseado em alguns achados como: Reclamação de dor em uma determinada região; presença de uma banda muscular sensível nessa determinada região; sensibilidade exagerada nessa banda sensível; restrição de movimento; reprodutibilidade clínica dos locais de dor quando palpado os PG e dor aliviada por alongamento ou injeção do PG. 
Durante o $4^{0}$ Congresso Mundial de Dor Miofascial ${ }^{27}$, realizado entre os dias 24 e 27 de agosto de 1998, na Itália, Arendet-Nielsen e col. ${ }^{27}$ reportaram que o dor muscular pode ser originada em experiências de diversas maneiras, como injeção intramuscular de substâncias algogênicas, estimulação elétrica, isquemia e contrações musculares excêntricas. As experiências sugerem que a magnitude da DR depende da intensidade e duração do processo no músculo responsável pelo processo de DR e também ao grau de hiperexcitabilidade central. Vecchiet ${ }^{27}$ reviu os tipos de dor muscular que podem existir após exercício. Durante a contração dinâmica do músculo, a dor nunca aparece nos mesmos quando não se atinge a carga de trabalho crítica (esforço crítico). Para cargas maiores, a dor está sempre presente em períodos mais curtos, conforme aumenta o esforço. A dor produzida por contrações isométricas é caracterizada por uma sensação de queimação, aumenta constantemente em intensidade até alcançar o processo de interrupção. As contrações dinâmicas excêntricas produzem dor que começam horas depois do fim do exercício e podem persistir por vários dias.

Ainda neste congresso de 1998, Hong ${ }^{27}$ afirmou que em um PG existem vários pontos sensíveis, os quais são formados de componentes sensitivos e componentes motores. Os componentes sensitivos representam o local de sensibilidade, que são largamente distribuídos por todo o músculo, mas estão concentrados na zona da placa. Atividade elétrica espontânea pode ser gerada nos componentes motores e que são zonas disfuncionais que liberam uma quantidade excessiva de acetilcolina. 
Simons ${ }^{27}$ em 1998 disse que há diferenças em PG centrais, localizados nas zonas motoras e os PG acessórios, causados por uma entidade em uma região das bandas tensas. Propôs que os PG são nódulos sensíveis e palpáveis em uma banda tensa; há presença de dor no final do alongamento total do músculo e reprodução da dor reclamada pelo paciente quando se comprime o PG. Ainda postulou que os PG podem ser identificados por ultra-som quando há fibrilação local no momento de inserção de uma agulha no mesmo; demonstração de picos de atividade elétrica espontânea, originadas nos componentes motores dos PG. Achados histológicos de nós contráteis, arredondados e fibras musculares densamente pigmentadas em cortes histológicos.

Stholer ${ }^{36}$ publicou um interessante artigo em 1999, em que descreveu conceitos das DTM relacionadas aos músculos. Apesar da seqüência de eventos que levam ao desenvolvimento das DTM de origem muscular não estar elucidada, atributos chaves como sensibilidade muscular à palpação, limitação de abertura bucal, alteração na oclusão dental e mudanças de humor são conseqüências já estabelecidas das DTM de origem musculares. Para padronizar o diagnóstico, foi desenvolvido pelo Instituto Nacional de Pesquisa Dental e Craniofacial, sob supervisão do Grupo de Pesquisa em Dor da Universidade de Washington, um sistema de diagnóstico para DTM $(\mathrm{RCD} / \mathrm{TDM})^{36}$. Consiste em um sistema de dois eixos. 01 consiste em descrição de dor ou dor presente na maxila, mandíbula, têmporas, face, região pré-auricular, dentro do ouvido, em função ou em repouso, conjuntamente com sensibilidade a palpação em 3 ou mais lugares em 20 
áreas pré-determinadas, com no mínimo um lugar sensível sendo do mesmo lado da queixa de dor. Os locais de palpação são os músculos temporais anteriores, médios e posteriores; origem, corpo e inserção dos masseteres; região mandibular posterior; região submandibular; região do pterigóideo lateral e tendão do temporal, nos lados esquerdo e direito. O 2 serve para avaliar a intensidade da dor, deficiência causada pela dor e presença de depressão e sintomas físicos não específicos. Ainda segundo o autor, a dor miofascial é uma dor loco-regional ,que quando associada a DTM, concentra-se nos músculos da mastigação. A dor regional pode estender para os músculos do pescoço e ombros. Ainda diz que o conceito clássico é a associação com PG que ativados produzem DR em outras partes do corpo. Lamentou que a maioria das observações feitas em indivíduos portadores de dor miofascial não são controladas e suscetíveis a tendências clínicas, o que pode ter como conseqüência a insuficiente compreensão dos processos de formação da dor miofascial, apesar da alta prevalência e significância clínica.

A transmissão e interpretação dos estímulos dolorosos pelo sistema nervoso central não são muito conhecidas, mas existem alguns artigos que tentam elucidar estes mecanismos. Sessle ${ }^{34}$ escreveu um destes em 1999, afirmando que as terminações nervosas periféricas provêem a base para a dor. Estas terminações muitas vezes atuam como nocioceptores, ou seja, órgãos que são ativados por estímulos nocivos localizados nos tecidos periféricos. O estímulo destas terminações pode resultar em produção de impulsos nervosos em fibras aferentes de pequeno diâmetro, como as fibras 
A-delta ou C, sendo então o estímulo conduzido até o cérebro, onde são processadas indicando a localização, intensidade, tipo e duração que este estímulo doloroso causou.

Estas fibras podem ainda responder por uma variedade de estímulos periféricos que causam dor em humanos como pressão exacerbada, substâncias químicas algógenas e agentes inflamatórios. Outro estímulo que pode vir a causar dor é a isquemia quando por um longo período e associada a contrações musculares, podendo a sensibilidade destas terminações ser aumentada com pressão moderada. Esta sensibilidade exacerbada das terminações é conhecida como sensitização periférica (SP), sendo resultado de uma resposta aumentada, um diminuto limiar de ativação e também de atividade nocioceptiva autônoma das fibras A-delta e C.

Porém as fibras citadas nos dois últimos parágrafos não fazem nada sozinhas, dependem de sensitização central para conseguirmos uma explicação de como os tecidos ficam sensíveis e doloridos após injúria ou doença. Estas explicações são úteis para um entendimento mais claro de algumas características de percepção de dor e também de formação de DR.

Branch; Carlson e Okeson ${ }^{1}$ em 2000 publicaram um interessante estudo no qual avaliaram a influência de consciência das áreas de DR em relatos de pacientes. Dizem que a sensibilidade muscular a palpação é um dos principais fatores que distinguem um paciente de DTM e um não paciente. A palpação muscular não é somente baseada em dados objetivos, pode conter muitos dados subjetivos, como o desejo do paciente colaborar com uma resposta positiva. Em grupos que não possuem DTM, também 
pode haver sensibilidade muscular, sendo então sugerido que esta sensibilidade pode ser causada pela palpação muscular. É um fato comum falso-positivo e falso-negativo ocorrerem em exames de palpação muscular, pois não há parâmetros de diagnóstico específicos de sensibilidade e especificidade desenvolvidos totalmente.

Segundo os autores, uma área em que a especificidade e sensibilidade são suspeitas é no relato da dor referida. Utilizaram 40 pacientes que procuraram a clínica para ajuda na resolução do quadro doloroso. Estes pacientes deviam ser portadores de DTM a mais de três meses, foi analisado somente o músculo masséter e o local de maior sensibilidade do músculo foi marcado após palpação manual. Após então foram palpadas as regiões demarcadas com um algômetro (Somedic), determinando-se assim o LDP. O grupo 1 foi composto por pacientes que não estavam conscientes das áreas de manifestação de DR. O grupo 2 por pacientes conscientes. Após os exames, o grupo 2 apresentou resultados maiores e estatisticamente significantes que o grupo 1 para presença de dor referida, inte nsidade e desconforto do que os pacientes do grupo 1. Para o LDP não houve diferenças estatisticamente significantes.

Após muito tempo sem publicações na área específica de dor referida facial, Wright ${ }^{48}$ em 2000 publicou um estudo no qual analisou o padrão de dor referida em pacientes com DTM. A avaliação foi feita somente por um examinador, no caso o próprio autor, palpando os seguintes músculos: temporal, masséter, trapézio, esplênio, esternocleidomastóideo, digástrico anterior e posterior. De acordo com os resultados obtidos pelo autor, para o 
músculo temporal a área mais comum de dor referida foi àregião do masséter. Para o masséter, foi a região de ATM e mandíbula. Para o trapézio, região frontal e occipital e para o músculo esternocleidomastóideo foi a região frontal. Os músculos que mais produziram dor referida foram trapézio, pterigóideo lateral e masséter respectivamente. As áreas em que o surgimento da dor referida foi mais comum foi à bochecha, orelha e fronte. Quando os pacientes reportavam a dor referida nos dentes, os pacientes também percebiam algum grau de dor na região alveolar, e gengiva do referido dente.

A importância de um correto diagnóstico também foi ressaltada no ano de 2001 por Konzelman, Herman e Comer. ${ }^{19}$ Através do relato de dois casos clínicos de pacientes que relataram dor em dentes, sendo que alguns destes respondiam positivamente a percussão. É clássico dos exames diagnósticos em odontologia que, a sensibilidade àpercussão é um indicativo de alteração pulpar. Esta alteração, em alguns casos, pode ser um diagnóstico decisivo, em que se decide tratar o dente endodonticamente ou extraí-lo. Os autores ainda relataram que apesar da extensa documentação que descreve o processo de DR que se origina de tecidos miofasciais para os dentes, não há muita atenção dos profissionais da odontologia a este fato. Em dois casos descritos, os pacientes possuíam dentes com sensibilidade espontânea e também com sensibilidade aumentada quando se pressionava o mesmo. Houve a realização de tratamento endodôntico e também extração dos dentes, sem que o processo de dor tenha sido resolvido. Por fim, os casos serviram como alerta para 
que, quando há uma dor em um dente sem que haja sinais clínicos e radiográficos de alguma alteração que possa levar a um processo doloroso, há a necessidade de se investigar se esta sensibilidade não é proveniente de pontos gatilho nos músculos, evitando assim mutilações e prejuízos financeiros aos pacientes.

Durante o ano de 2001, Drobek; De Laat e Schoenaers ${ }^{4}$ observaram o limiar tátil e LDP durante o tratamento da dor orofacial. Somente um examinador treinado avaliou os pacientes ,e após esta avaliação, dividiu os pacientes em três grupos. O primeiro foi de pacientes que possuíam dor de origem muscular (7 pacientes). O segundo, dor articular e muscular (11 pacientes) e o terceiro e último grupo, dor neuropática (8 pacientes).

Para o limiar tátil, não houve diferenças entre os exames iniciais e os exames depois de iniciado o tratamento. Para o LDP, as mudanças foram esporadicamente significantes, o que implica que mudanças neste parâmetro objetivo de avaliação não reflete sempre em uma melhora do quadro clínico dos pacientes. Este período curto de avaliação, 6 semanas pode não ser suficiente para que o exame não detecte alg um tipo de mudança, sendo o exame não sensível para este período. Também para o período acima de 6 semanas, não houve mudanças significantes no LDP, contrastando com a escala VAS, a qual revelou significante melhora do estado doloroso dos pacientes. Os autores concluíram que estes achados contrastam com muitos estudos, sendo necessário uma investigação maior para analisar os motivos de tais resultados. 
Em 2001, Svensson e Graven-Nielsen ${ }^{37}$ revisaram a literatura objetivando verificar os mecanismos e manifestação clínica das dores miofasciais. Após os tecidos musculares serem submetidos a cargas pesadas e períodos insuficientes de relaxamento, contrações dinâmicas e isométricas irá produzir dor muscular o que provavelmente envolve a mesma patofisiologia do processo que causa dor por isquemia. A isquemia por si só muitas vezes não é capaz de causar dor, mas quando há combinação com fortes contrações musculares, há surgimento de fortes dores em humanos. Algumas substâncias como lactato, potássio ou falta de oxidação dos metabólitos, conjuntamente com fatores mecânicos como número de contrações, duração e força podem ter um papel significante no desenvolvimento da dor. Somando-se a estes fatores, hipoxia, liberação de bradicinina, prostaglandinas e calcitonina gene-relacionada, adicionadas a um $\mathrm{pH}$ reduzido, podem sensitizar os nocioceptores musculares e desenvolver dor que surge com estímulos mecânicos durante as contrações musculares.

Mense e Simons ${ }^{22}$ em 2001 escreve ram que a dor miofascial é detectável devido à presença de PG. O paciente reclama de dor em uma determinada região e ao examinar-se o local indicado pelo paciente, o mesmo apresenta-se com a musculatura dolorida e restrição de movimento. Apresenta também um ponto mais sensível, que se caracteriza como um nódulo palpável em uma banda muscular tensa. A pressão neste ponto sensível aumenta ou causa dor no local que o paciente alertava como ser a fonte do processo álgico. Não se sabe ao certo a prevalência da dor de 
origem miofascial, porém estima-se que mais de $30 \%$ da população possua esta alteração no tecidos musculares. Os autores ainda tecem algumas classificações que não podem ser ignoradas. Definem a palavra dor como sendo uma experiência sensorial e emocional desagradável, com danos teciduais potenciais ou reais. Afirmam que dor referida é a sensação dolorosa sentida em um determinado local, mas o lugar de origem da dor não é o mesmo em que ela está se manifestando, o que não impede de ocorrer dor no local de origem concomitantemente com o processo doloroso referido.

Mense e Simons ${ }^{22}$ ainda em 2001 descreveram de uma maneira simplificada como a dor aguda pode caminhar para um processo crônico de sensitização dos nocioceptores. Primeiramente há uma lesão tecidual e como conseqüência a liberação de substâncias neurovasoativas como bradicininas, prostaglandinas e histaminas. Estas substâncias agem nas células endoteliais dos vasos sanguíneos causando vasodilatação e aumento da permeabilidade vascular, resultando clinicamente em um edema. Simultaneamente estas substâncias neurovasoativas também atuam sobre os receptores nocioceptivos vizinhos ao local da lesão e a excitação das terminações nervosas levam a liberação de substâncias armazenadas nas mesmas, como substância $\mathrm{P}$ e peptídeo calcitonina gene-relacionada. Estas substâncias, principalmente a substância $P$ possui ação vasodilatadora, o que aumenta o edema na região. Normalmente o que acontece é o reparo da lesão com conseqüente redução no edema e desaparecimento do quadro doloroso e da sensibilidade local, porém em 
algumas situações, o edema aumenta de tamanho e acaba por comprimir as vasos sanguíneos da região, o que acarretaria na falta de suprimento de sangue para o tecido danificado e conseqüente isquemia. Esta isquemia é um potente fator na liberação de bradicininas e conseqüentemente tem-se um circulo vicioso formado que é responsável pela manutenção do edema e sensitização das terminações nocioceptivas periféricas. O problema é que se este ciclo não for interrompido com um tratamento adequado ele pode persistir por um longo período.

Em 2001, Mense e Simons ${ }^{23}$ escrevem um capítulo em que explicam os mecanismos da formação e condução da dor referida. Basicamente há uma teoria proposta por Rugh, sendo nomeada de Teoria da projeçãoconvergência. Existem algumas outras, como a teoria proposta por McKenzie que é a Teoria da facilitação-convergência. Ambas deixam claro que o SNC em seus níveis mais altos, não é capaz de localizar corretamente a lesão, pois as informações que provêm de neurônios em centros mais baixos, como a medula espinhal, estão equivocadas. A razão para tal fato é que as conexões dos neurônios periféricos convergem nos centros inferiores de tal maneira que os centros superiores não conseguem identificar a origem real da dor.

Para explicar o mecanismo de formação e atuação dos PG, Mense e Simons $^{24}, 2001$, escreveram um excelente e esclarecedor capítulo de livro, no qual descrevem os processos de formação dos $P G$, as teorias de falta de energia, excesso de cálcio extracelular, achados eletromiográficos e 
achados histológicos que podem explicar, ou melhor, tentam elucidar algumas características dos PG. 
Proposição 
Proposição.doc

\section{3 - Proposição}

Baseado no exposto, os objetivos deste estudo são:

a) - Determinar um intervalo de pressão àpalpação que cause o

processo de dor referida em pacientes portadores de dor miofascial.

b) - Quantificar um intervalo de tempo de manutenção de pressão para que haja o desencadeamento ou intensificação do processo de dor referida nestes pacientes.

c) - Verificar o padrão de dor referida originado nos músculos palpados. 
Material e Métodos 


\section{4 - Material e Métodos}

\section{1 - Material}

\subsection{1 - Amostra}

Para este estudo foram avaliados 44 indivíduos, divididos em dois grupos, sendo o grupo A composto por 24 pacientes portadores de dor miofasciale o grupo B composto por 20 indivíduos assintomáticos.

Os pacientes do grupo A foram selecionados dentre aqueles que procuraram tratamento na Clínica de Disfunção Temporomandibular da Faculdade de Odontologia de Bauru, da Universidade de São Paulo com queixa de dores na região de cabeça e pescoço. Foram, então, submetidos a anamnese e examefísico, para determinar se eram portadores de Dor Miofascial. Os pacientes examinados com DTM de origem articular ou muscular (diferente de dor miofascial), portadores de sensibilidade muscular generalizada como fibromialgia, que estavam utilizando algum tipo de medicação, realizando 
Métodos.doc

algum tipo de tratamento específico para DTM ou possuidores de distúrbios psicológicos foram excluídos da amostra.

O grupo B foi composto por 20 indivíduos que não apresentavam quaisquer tipos de sinais e sintomas de DTM e foram selecionados aleatoriamente entre os que buscaram tratamento, exclusivamente odontológico, nas clínicas da Faculdade de Odontologia de Bauru da Universidade de São Paulo. Indivíduos que tomavam algum tipo de medicação analgésica, com distúrbios psicológicos ou sistêmicos não foram inclusos no estudo.

\subsection{2. - Fichas utilizadas para o estudo}

Para a realização dos exames, os pacientes leram e assinaram dois documentos:

$$
\begin{aligned}
& \text { A - Carta de informação ao paciente (Anexo 1) } \\
& \text { B - Termo de Consentimento (Anexo 2) }
\end{aligned}
$$

Para a anotação dos dados, foi utilizada uma ficha denominada Ficha de Exame. 
Métodos.doc

4.1.2.1. - Carta de informação aos pacientes e termo de consentimento

Estes documentos foram entregues a cada indivíduo selecionado previamente ao exame. Nelas os procedimentos realizados, propósitos do estudo, riscos e benefícios da participação de cada um estão descritos de maneira clara e em linguagem não técnica. O termo de consentimento trazia obrigatoriamente a assinatura do paciente e do examinador.

\subsubsection{2. - Ficha de Exame}

Foi desenvolvida para organizar os dados obtidos pelos exames, sendo preenchida após o paciente ter lido a carta de informação aos pacientes e assinado o termo de consentimento.

Nesta ficha estavam informações sobre:

- Identificação do grupo estudado

- $\quad$ Identificação do paciente (nome)

- Informações gerais (idade, gênero, endereço e telefone)

- $\quad$ Tempo, pressão de palpação e local de dor referida. 
Métodos.doc

\subsection{3. - Examinador}

O exame foi realizado por apenas um examinador, sendo este cirurgiãodentista, aluno do curso de pós-graduação em Reabilitação Oral, em nível de Mestrado, da Faculdade de Odontologia de Bauru da Universidade de São Paulo.

O examinador recebeu treinamento intensivo para a correta identificação e localização dos PG, familiarização com o aparelho e padronização do exame em relação à intensidade de aplicação de força, definida em $1 \mathrm{~kg} / \mathrm{cm}^{2} / \mathrm{s}$. Toda esta etapa de treinamento foi supervisionada por um profissional experiente no diagnóstico e tratamento das DTM.

Uma segunda pessoa participou do exame somente como anotador, ficando a cargo desta escrever os valores obtidos pelo exame de palpação, tempo de palpação e local de manifestação da DR. 
Métodos.doc

\subsection{4 - Algômetro}

O exame de palpação teve por finalidade neste estudo verificar o Limiar de Dor àPressão, obtido com o auxílio de um algômetro da marca Kratos ${ }^{\circledR}$. (Figura 4.1)

Este algômetro é um dinamômetro que pode medir forças de pressão ou tração em Kgf ou daN (Dina). O aparelho possui uma haste em uma das extremidades, que se rosqueia uma ponta metálica circular (Figuras 4.2 e 4.3). plana com área de $1 \mathrm{~cm}^{2}$, que entra em contato com a pele do paciente no momento do exame e era equivalente àponta do dedo indicado $r$, comumente utilizado para os procedimentos de palpação nos exames para DTM.

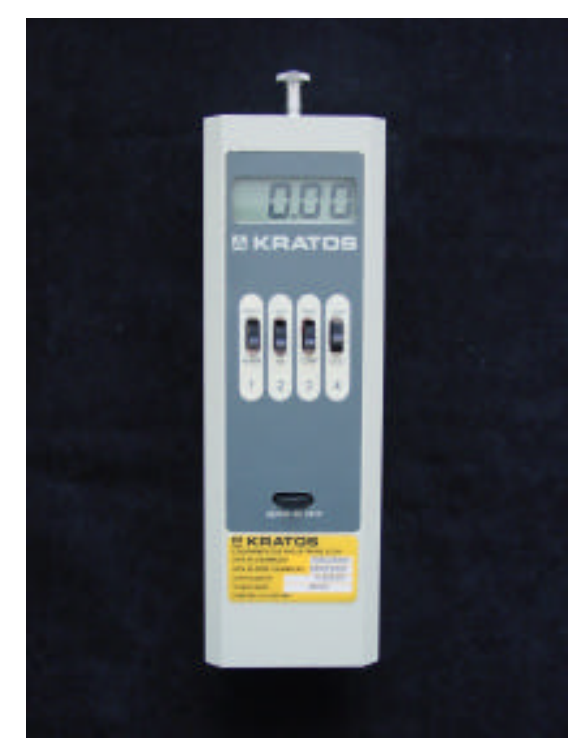

Figura 4.1 - Algômetro $\operatorname{Kratos}^{\circledR}$ utilizado no exame de palpação muscular. 
Métodos.doc

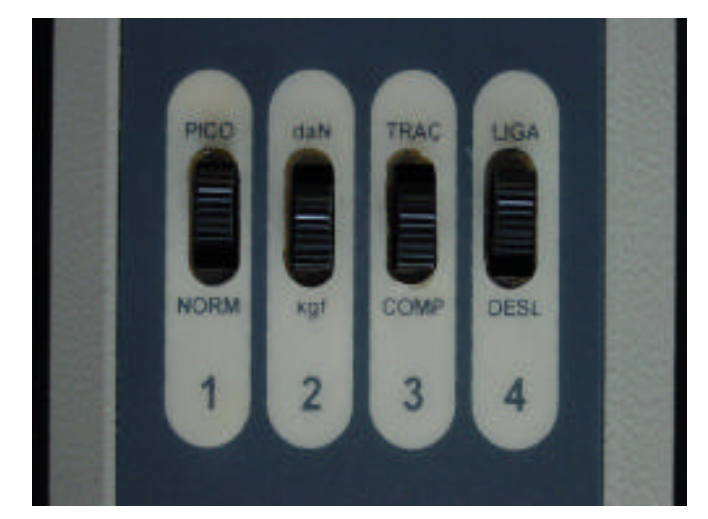

Figura 4.2 - Painel de controle do aparelho.

Chave 1 - Registra o maior valor de pressão obtido na palpação.

Chave 2 - Controla a unidade de pressão desejada.

Chave 3 - Tipo de força (tração ou pressão).

Chave 4 - Liga e desliga o aparelho.

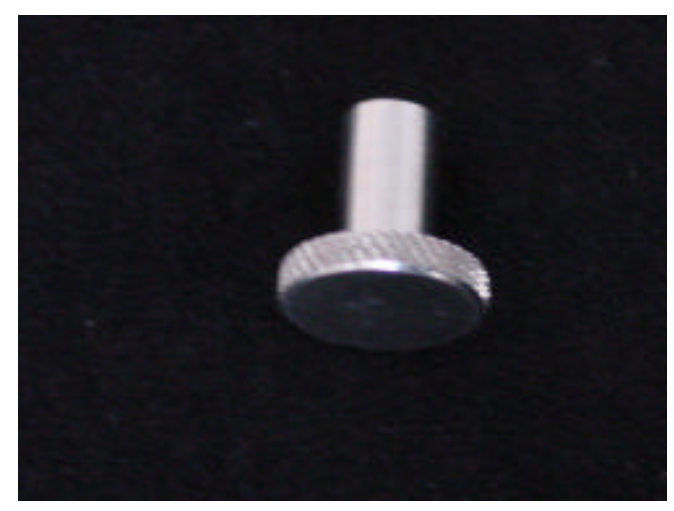

Figura 4.3 - Ponta circular chata que entra em contato com a pele do paciente (diâmetro $=1 \mathrm{~cm})$ 
Métodos.doc

\section{2 - Métodos}

4.2.1 - Localização dos Pontos Gatilho

Os 24 pacientes do grupo A foram avaliados por um examinador calibrado que estimou o padrão de dor referida, tempo necessário de manutenção da pressão e a quantidade de pressão necessária para desencadear DR.

Um exame para determinar a presença e local dos PG foi realizado primeiramente. Estes, após detectados, eram demarcados e então, iniciado o exame depressão e tempo propriamente ditos.

4.2.2 - Procedimentos do Exame 
Métodos.doc

A deteç̧ão dos PG, iniciou-se com o exame e preenchimento da Ficha de Exame. Foram anotados o grupo que o paciente pertence, nome, informações gerais e músculo(s) a ser(erem) palpado(s).

Nos indivíduos assintomáticos (grupo B), os músculos palpados foram o temporal (anterior, médio e posterior) e o masséter (corpo). Na porção anterior do músculo temporal, o ponto palpado localizourse a $30 \mathrm{~mm}$ do ponto mais posterior da órbita e $15 \mathrm{~mm}$ acima da extremidade superior do arco zigomático. Para a porção medial, o ponto estava a $60 \mathrm{~mm}$ ao longo de uma linha vertical imaginária perpendicular à outra linha do canto do tragus ao centro do meato acústico externo. Para a porção mais posterior do músculo temporal, o ponto palpado estava a $40 \mathrm{~mm}$ para posterior do local marcado na porção média do temporal. Para o músculo masseter, após a localização do mesmo, determinava-se o ponto médio entre a origem no arco zigomático e a inserção no ângulo da mandíbula.

Para o grupo sintomático, além dos músculos já descritos, o esternocleidomastóideo e a porção superior do trapézio também foram examinados. Para estes músculos, não foi utilizado o aparelho, devido à diferença técnica de palpação destes músculos quando comparados aos anteriormente descritos, sendo utilizada a técnica de palpação digital através de pinçamento (Figura 4.6 e 4.7). Como não foi utilizado nos últimos o algômetro para a realização da palpação muscular, não foi observado o LDP, sendo 
Métodos.doc

somente observado o padrão de dor referida e tempo necessário de pressão para desencadear o processo de dor.

Antes de iniciar o exame, o paciente foi instruído que deveria avisar de maneira clara (levantando a mão esquerda com o punho cerrado) o momento exato em que a pressão inicial sentida era convertida em processo doloroso. Foi enfatizado que o paciente não deveria suportar a dor, e sim comunicar imediatamente qualquer sensação de dor local. Foi também instruído ao paciente que se ele sentisse durante o procedimento alguma dor que não fosse no local palpado, ele deveria avisar abrindo a mão esquerda. Quando o paciente levantava a mão esquerda com o punho cerrado, o tempo era tido como zero e quando o mesmo abria a mão esquerda, o cronômetro era travado e o tempo então anotado.

Em ambos os grupos, a palpação foi realizada com auxílio do algômetro com a ponta do mesmo perpendicular à pele que recobria o $\mathrm{PG}$, de forma gradual e constante, até que o paciente acusasse dor no local palpado. Neste momento, o valor da pressão era anotado.

Nos músculos masséter e temporal, foi utilizado o algômetro, sendo possível assim quantificar a pressão necessária para causar dor referida quando palpados os PG nestes músculos (figura 4.4 e 4.5). 
Métodos.doc

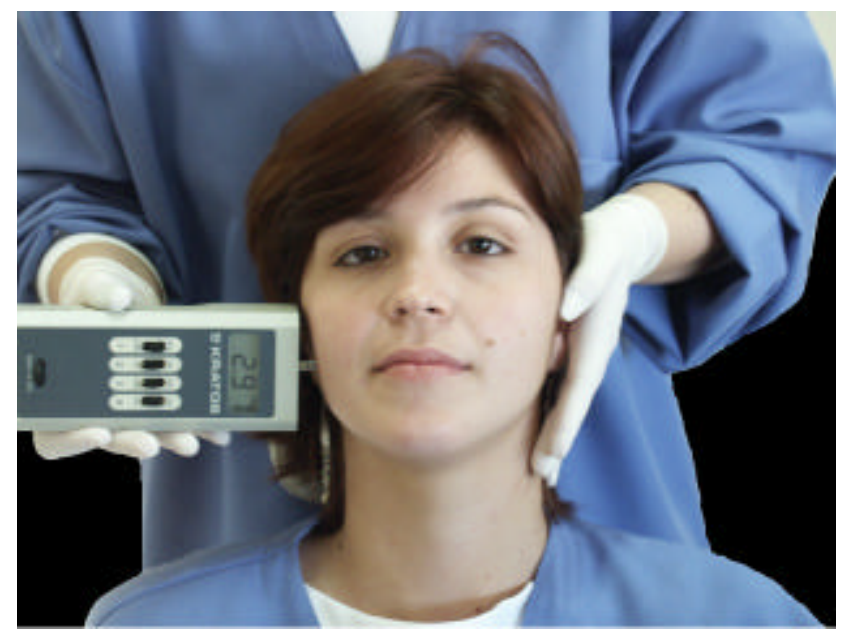

Figura 4.4 - Pressão realizada no corpo do músculo masséter.

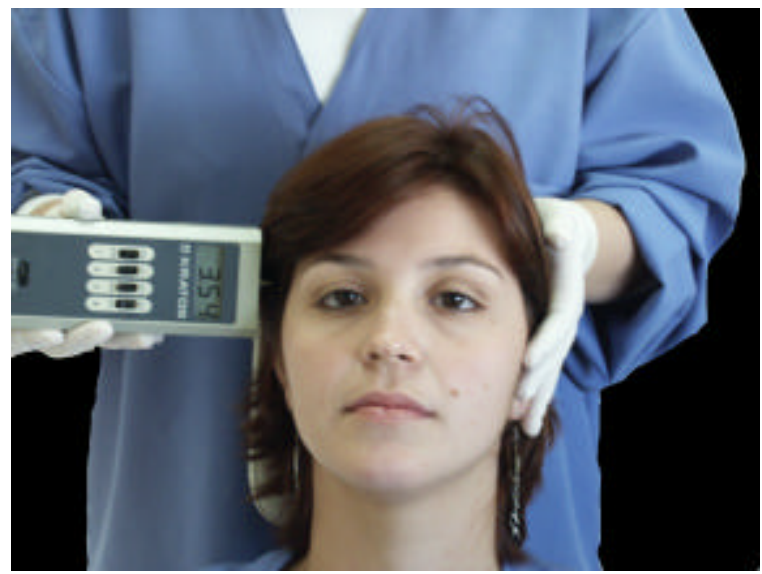

Figura 4.5 - Palpação realizada na porção média do músculo temporal 


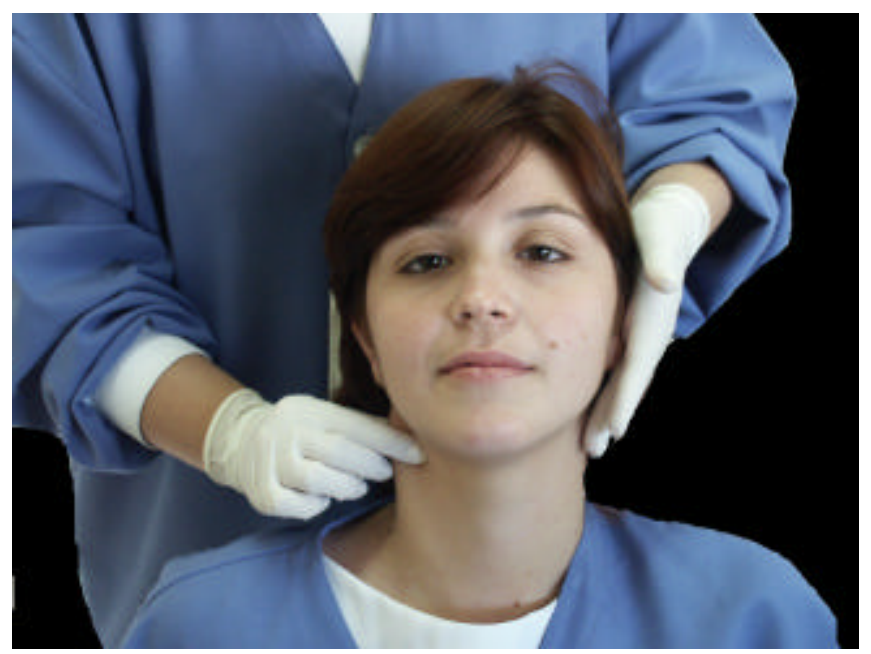

Figura 4.6 - Palpação do músculo esternocleidomastóideo

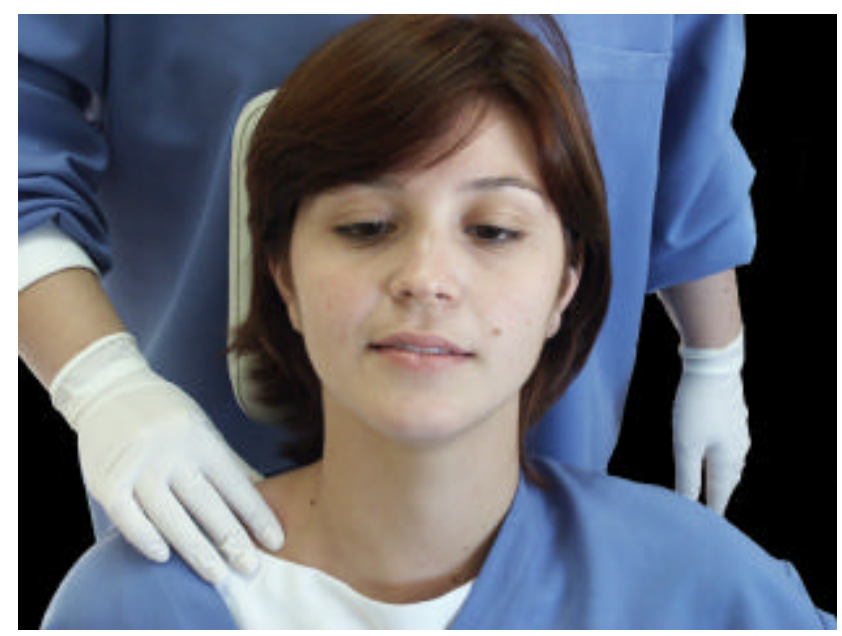

Figura 4.7 - Palpação do músculo trapézio 
Métodos.doc

Quando era realizada a pressão nos músculos temporal e masséter, uma mão empunhava o aparelho e a outra servia de anteparo àcabeça do paciente, de forma que não houvesse movimentação da cabeça do mesmo, o que prejudicaria o resultado do exame. A cabeça do paciente estava também durante o tempo todo apoiada no encosto da cadeira odontológica.

\subsubsection{Análise Estatística}

Foi utilizado o teste t de Student para verificar se havia diferenças estatisticamente significantes entre os grupos estudados, adotando o nível de significância de 1\%.

Para a avaliação do padrão de dor referida, foi realizada somente estatística descritiva devido aos resultados não serem numéricos, e sim caracteres.

O tempo de pressão para cada grupo muscular foi medido em segundos, calculado a média, desvio padrão e aplicado o teste ANOVA a 1 critério para ver se havia diferenças entre o tempo de pressão nos músculos no grupo B. 
Resultados 
$\underline{\text { Resultados.doc }}$

\section{5 - Resultados}

Após a seleção de pacientes de acordo com os critérios previamente estabelecidos e a realização dos exames já citados, o grupo B totalizou 24 pacientes (23 mulheres e 1 homem) com idade média de 37,5 anos. Ao todo foram 38 PG palpados nos músculos já descritos, totalizando 32 músculos. $\bigcirc$ grupo A contou com 20 indivíduos (10 mulheres e 10 homens) analisados, sendo a média de idade neste grupo de 30 anos. Os resultados obti dos serão descritos a seguir, divididos em tópicos:

5.1 - Quantidade de Pressão.

5.2 - Tempo de Pressão.

5.3 - Músculos afetados e áreas de manifestação de dor referida. 
$\underline{\text { Resultados.doc }}$

\section{1 - Quantidade de Pressão}

Após os exames de palpação feitos com o auxílio de um algômetro, a média dos valores obtidos em relação à quantidade de pressão exercida nos PG dos pacientes portadores de dor miofascial, número de pacientes e desvio padrão, estão descritos na tabela 5.1 .

Tabela 5.1 - Número de pacientes, média de pressão e desvio padrão do grupo A (sintomáticos).

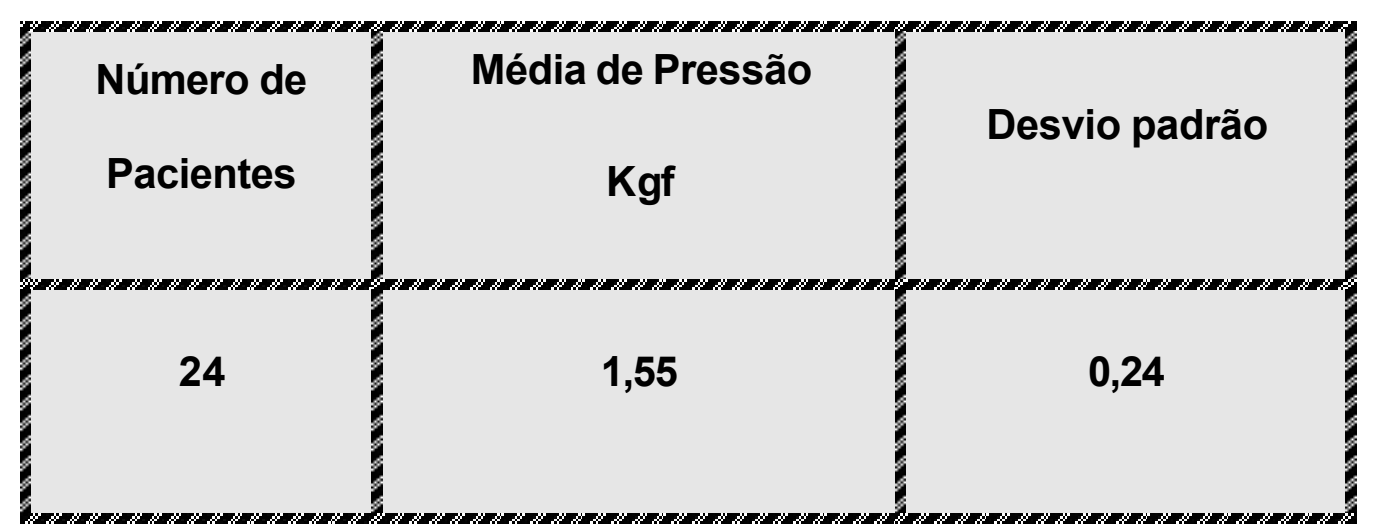


$\underline{\text { Resultados.doc }}$

Para o grupo B, que representa os indivíduos assintomáticos, os valores médios obtidos dos exames de palpação, desvio padrão e quantidade de pessoas estão descritos na tabela 5.2 .

Tabela 5.2 - Número de pacientes, média de pressão e desvio padrão do grupo B (Sintomático).

\begin{tabular}{|c|c|c|}
\hline Número de Indivíduos & Média de pressão Kgf & Desvio Padrão \\
20 & 3,84 & 0.90 \\
\hline
\end{tabular}


$\underline{\text { Resultados.doc }}$

\section{2 - Tempo de Pressão}

O tempo de pressão foi medido com um cronômetro(em segundos) e anotado a partir do momento em que se iniciava a dor no PG até o momento em que era relatado o surgimento ou agravamento da dor referida nos pacientes. A média obtida foi de 7,29 segundos, com desvio padrão de 2,7 . Os valores estão distribuídos conforme o gráfico abaixo:

\section{Tempo de Pressão}

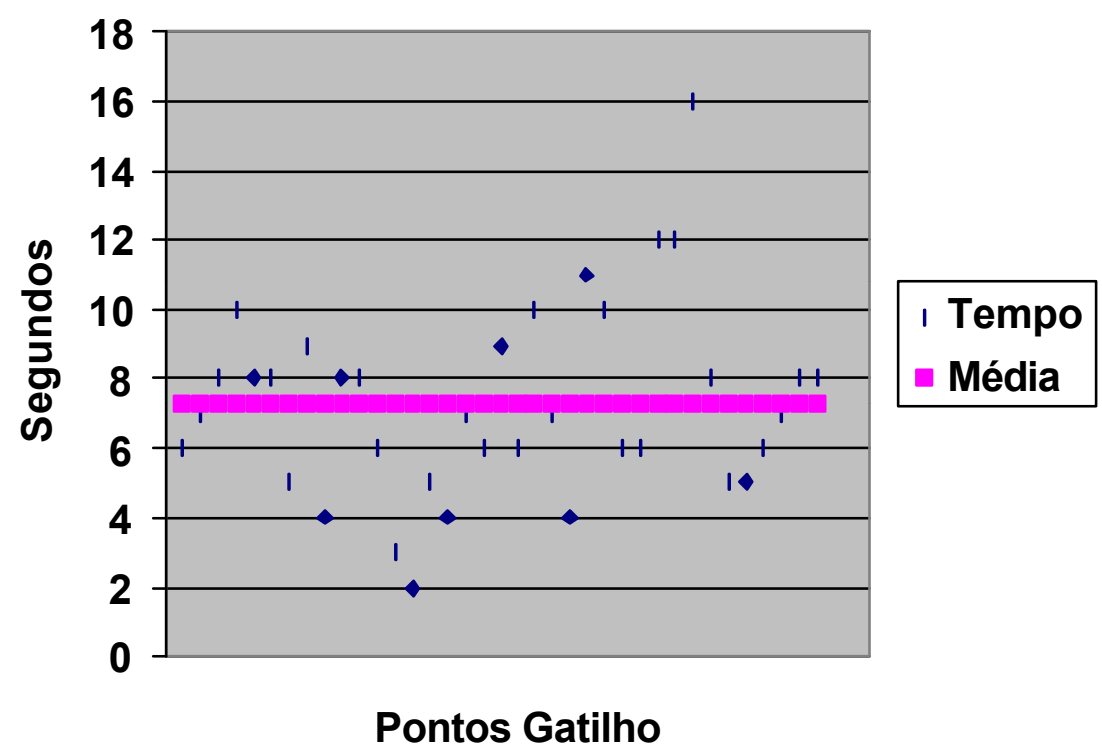

Figura 5.1 - Cada ponto em azul representa o tempo de pressão mantido em cada PG que foi necessário para desencadear o processo de DR. A linha colorida representa a média dos vários tempos. 
$\underline{\text { Resultados.doc }}$

Para cada grupo muscular examinado, foi feita a média do tempo de palpação, sendo os resultados apresentados na tabela 5.3.

Tabela 5.3 - Média de tempo de palpação em cada músculo.

\begin{tabular}{|c|c|c|}
\hline & Média & Desvio Padrão \\
\hline \multirow[b]{2}{*}{ Esternocleidonatóideo } & 6.20 & 3.01 \\
\hline & & \\
\hline Direito & 7.66 & 1.78 \\
\hline \multirow[t]{2}{*}{ Esquerdo } & 7.62 & 2.73 \\
\hline & & \\
\hline Direito & 7.66 & 3.81 \\
\hline Esquerdo & 7.00 & 1.15 \\
\hline Direito & 6.33 & 0.00 \\
\hline \multirow{2}{*}{ Trapézio } & 6.66 & 4.50 \\
\hline & 7.00 & 1.53 \\
\hline
\end{tabular}


$\underline{\text { Resultados.doc }}$

\section{3 - Padrão de Dor Referida}

\subsection{1 - Músculo Masséter}

As regiões de manifestação da DR para o músculo masséter podem ser vistos na tabela 5.4 .

Tabela 5.4 - Locais de manifestação de DR no músculo masséter.

\begin{tabular}{||c|c|c|l||}
\hline Masséter & \multicolumn{1}{|c|}{ Origem } & \multicolumn{1}{|c||}{ Corpo } & \multicolumn{1}{||}{ Inserção } \\
\hline Área de & \multicolumn{1}{|c||}{ Ouvido, } & \multicolumn{1}{|c||}{ Maxila, } & \multicolumn{1}{c||}{ ATM, } \\
DR & ATM & Processo alveolar & músculo \\
& & da maxila, ATM e & temporal, \\
& & ouvido. & processo alveolar \\
& & & inferior. \\
\hline
\end{tabular}


$\underline{\text { Resultados.doc }}$

Em todos os casos o processo de DR se manifestou do lado ipsilateral ao músculo afetado.

\subsection{2 - Músculo Temporal}

Os padrões de dor para o músculo temporal estão descritos na tabela

5.5. Nestes casos também não houve dor referida que cruzasse a linha média.

Tabela 5.5 - Áreas de DR manifestadas pelo músculo temporal.

\begin{tabular}{|c|c|c|}
\hline & Músculo & Áreas de DR \\
\hline Temporal & $\begin{array}{l}\text { anterior } \\
\text { médio } \\
\text { posterior }\end{array}$ & $\begin{array}{l}\text { Processo mastóideo, frontal, } \\
\text { masséter, esternocleidomastóideo. }\end{array}$ \\
\hline
\end{tabular}


$\underline{\text { Resultados.doc }}$

\subsection{3 - Músculo Esternocleidomastóideo}

Este músculo apresentou áreas de DR que se encontram descritas na tabela 5.6. Para este músculo, houve relatos de DR cruzando a linha média, quando esta manifestava na região frontal.

Tabela 5.6 - Regiões de manifestação de DR do esternocleidomastóideo.

\begin{tabular}{|l|c|}
\cline { 2 - 2 } \multicolumn{1}{c|}{} & Esternocleidomastóideo \\
\hline Áreas de Dor Referida & Maxila, frontal, temporal, \\
& occipital, processo mastóideo, ATM e \\
& ombro. \\
\hline
\end{tabular}


$\underline{\text { Resultados.doc }}$

5.3.4 - Músculo Trapézio

Os resultados estão inseridos na tabela 5.7 e também não houve relato de DR cruzando a linha média.

Tabela 5.7 - Padrão de DR apresentado pelo músculo trapézio.

\begin{tabular}{|c|c|}
\hline & Músculo Trapézio \\
\hline Áreas de DR & Ângulo da mandíbula, \\
& $\begin{array}{r}\text { processo mastóideo, temporal, } \\
\text { occipital, repuxamento do braço. }\end{array}$ \\
\hline
\end{tabular}


$\underline{\text { Resultados.doc }}$

\section{4 - Análise Estatística}

5.4.1 - Quantidade de Pressão

Para a comparação dos valores obtidos entre os grupos foi utilizado o teste t de Student, descrito na tabela seguinte.

Tabela 5.8 - Teste "t" de Student para os grupos estudados.

\begin{tabular}{|l|r|r|c|}
\hline & $\begin{array}{c}\text { Média } \\
\left(\mathrm{kg} / \mathrm{cm}^{2}\right)\end{array}$ & $\begin{array}{c}\text { Desvio } \\
\text { Padrão }\end{array}$ & $\begin{array}{r}\text { Número } \\
\text { Indivíduos }\end{array}$ \\
\hline Controle & 3.841000 & 0.904438 & 20 \\
\hline $\begin{array}{l}\text { Dor } \\
\text { Miofascial }\end{array}$ & 1.573000 & 0.253400 & 20 \\
\hline
\end{tabular}

Valor de $t=10.7986468(p<0,01)$ 
$\underline{\text { Resultados.doc }}$

De acordo com a análise estatística, diferenças estatisticamente significantes foram detectadas na comparação entre os valores das médias entre os dois grupos analisados, sendo que a pressão suportada pelo grupo controle foi maior que a pressão suportada pelo grupo de pacientes com dores miofasciais.

5.4.2 - Tempo de Pressão

Tabela 5.9 - Teste Anova a 1 critério e Teste de Tukey para o tempo de pressão.

\begin{tabular}{|c|c|c|}
\hline Músculo & Média & Desvio Padrão \\
\hline Esternocleidomastóideo & $7,00 \mathrm{seg}$. & 1.41 \\
\hline Trapézio & $7,00 \mathrm{seg}$. & 0.00 \\
\hline Masséter & $8,00 \mathrm{seg}$ & 0.70 \\
\hline Temporal & $6,50 \mathrm{seg}$ & 0.00 \\
\hline
\end{tabular}

p $\quad 0,01$

Não houve diferenças estatisticamente significantes entre os músculos palpados. 
Discussão 


\section{6 - Discussão}

O correto diagnóstico das DTM é de suma importância para um adequado planejamento e tratamento, especialmente quando tratamos de indivíduos portadores de dor miofascial, pois podem existir locais de dor que não são a fonte do problema, ou seja, o ponto causador do processo doloroso não está localizado necessariamente onde o paciente aponta como sendo o local de queixa principal. ${ }^{6,15,38}$ Conseqüentemente, uma incorreta localização do ponto exato que desencadeia o processo de dor, faz com que não se consiga controlar o problema de maneira adequada, o que pode causar transtornos físicos e emocionais ao paciente, pois a condição dolorosa irá persistir por mais tempo. Este fato pode afetar a vida do paciente, podendo também haver mutilações, como extrações desnecessárias ou tratamentos endodônticos de elementos dentais que não são a fonte do problema. Ainda, prejuízos financeiros são comuns, pois o paciente despenderá tempo e dinheiro por tratamentos inadequados. ${ }^{22,28,31,48} \mathrm{Em}$ função destes fatos, fica evidente que é imprescindível e imperativo que uma correta anamnese e exame físico devem ser realizados de maneira criteriosa, possibilitando ao profissional diagnosticar corretamente as alterações que levam a queixa principal. ${ }^{26,31,38,42}$ 
Estes pontos, quando ativados, podem causar dor em outra região, que não a região palpada, sendo esta dor conhecida como dor referida. Acontecendo este evento, o PG responsável pelo surgimento da DR é conhecido como PG ativo. Este ponto ativo desencadeia dor espontaneamente, ou quando há algum tipo de estímulo, como contração do músculo ou palpação deste PG. Há também um segundo tipo de PG, sendo que este não causa DR espontaneamente, sendo evidenciado quando há a palpação muscular. O paciente possui uma sensibilidade maior, ou mesmo dor, somente no local palpado. Este tipo de PG é denominado como latente. 6,11,12,22,24,29,31,38,39,42,48

A ativação dos PG é comumente associada a algum grau de abuso, ou sobrecarga do músculo, podendo ser aguda, mantida ou repetitiva. Um músculo mantido em uma posição contraída pode ativar PG latentes, desencadeando desta maneira o processo de DR. Normalmente o paciente está ciente da dor causada por um PG ativo, mas pode não estar informado da disfunção que o mesmo pode causar. Já em relação à dor originada por PG latentes, o paciente só se torna ciente da dor que ele origina quando uma pressão é aplicada diretamente sobre o mesmo. A dor referida espontânea pode surgir quando há um aumento da irritabilidade dos PG. ${ }^{7,12,24}$

Os PG causam disfunções locais que podem produzir não somente dor à distância, mas também distúrbios sensoriais como hipertermia cutânea, lacrimejamento, fraqueza e diminuição da capacidade de trabalho do músculo envolvido. Distúrbios de sono também podem ser achados em pacientes 
portadores de dor miofascial. Estes distúrbios podem aumentar a sensibilidade dos PG, o que pode aumentar o processo de dor sentido pelo paciente. Um outro fator a ser considerado é a posição de dormir nas pessoas que apresentam dor miofascial. Posições não adequadas podem ativar ou aumentar a sensibilidade dos PG, o que poderia acarretar em distúrbios do sono. ${ }^{7,12,24,}$ 39,42

Alguns achados no exame físico são característicos dos portadores de dor miofascial. Bandas tensas, nódulos sensíveis, reconhecimento da dor referida quando palpado o PG, fibrilação local em resposta a uma palpação rápida e vigorosa, músculos afetados com limitação de movimento, a dor quando o músculo é forçado a se contrair contra resistência e fraqueza muscular, pois como os músculos afetados já estão com fadiga, este processo é agreavado mais rapidamente e se cansam de maneira precipitada quando comparado com músculos normais. $6,7,11,12,24,31$

Um dos exames padrão para os pacientes portadores de dor miofascial é a palpação muscular digital manual, através da qual localiza-se os pontos sensíveis e assim pode-se tratar o problema de maneira adequada. A grande dificuldade deste exame é que devido àvariação de fo rça aplicada pelos profissionais, pode haver confusão no diagnóstico devido à força ser aplicada de maneira exacerbada ou então uma pressão digital não suficientemente vigorosa que contribua para a execução de um correto diagnóstico. $5,7,16$ 
Para tentar minimizar o processo citado acima, houve então a tentativa de se desenvolver aparelhos que medissem, ou melhor, quantificassem a força aplicada nas estruturas musculares e articulares para uma correta padronização e conseqüente diagnóstico mais preciso. Estes aparelhos podem ser conhecidos como algômetros ou palpômetros, que são dinamômetros e, através de uma ponta circular com uma área pré-determinada pelo fabricante, aplica-se uma força na estrutura a qual se quer analisar. ${ }^{2,5,16} \mathrm{~A}$ algometria é a medição da sensibilidade em resposta a uma força aplicada perpendicularmente àpele. Existem três finalidades na utilização do algômetro em pacientes com dor miofascial. A primeira é quantificar o LDP do local onde se aplica àforça; a segunda é a força responsável pelo surgimento da DR e a terceira é a tolerância do paciente a força aplicada. ${ }^{24}$

Há vários tipos de algômetros e os estudos mostram que estes são aparelhos que possuem uma boa reprodutibilidade, ou seja, possuem uma repetição de resultados adequada, mesmo que se varie o examinador, característica esta ideal para a utilização do aparelho, pois indica que o aparelho consegue medir a quantidade de pressão aplicada de maneira fiel, mesmo que se variem os examinadores..$^{2,3,5,11,12,15,16,21}$ Segundo Mense e Simons ${ }^{24}$, o algômetro é uma ferramenta útil de medição da sensibilidade, desde que o examinador não esteja somente preocupado em ver os números que aparecem no visor do aparelho. Os números por si só não indicam nada sobre a fonte de dor ou a causa da dor, pois a sensibilidade pode ser causada 
por várias entidades patológicas, como PG da dor miofascial, pontos sensíveis da fibromialgia, bursite, espasmo severo e outras alterações. A causa da sensibilidade deve ser estabelecida em conjunto com outros testes diagnósticos. ${ }^{24}$

Mense e Simons ${ }^{24}$ ainda afirmaram que a utilização dos algômetros requer treinamento do examinador para manuseá-lo corretamente e localizar o local sensível para que possa ser feita a medição. A localização precisa do PG deve ser feita antes através de exame digital e com a cooperação do paciente, após o que, a ponta do algômetro deve ser colocada sobre o ponto sendo que a mesma deve permanecer o tempo todo do exame no local, sem que haja desvios, pois na presença destes, pode haver uma leitura errônea dos valores mostrados pelo aparelho.24

As comprovações das afirmações feitas no parágrafo acima vêm dos estudos realizados por Hong e col. ${ }^{11}$ que utilizaram o algômetro para avaliar PG ativos e latentes no músculo extensor digital comum do dedo médio. Três pontos de avaliação foram examinados. Um PG (A), na banda muscular tensa a $2 \mathrm{~cm}$ distalmente ao $\mathrm{PG}(\mathrm{B})$ e em uma faixa de músculo normal localizado a 1 $\mathrm{cm}$ distal e $1 \mathrm{~cm}$ lateral a banda muscular retesada (C). Os autores avaliaram três parâmetros em cada local analisado o LDP, a quantidade de pressão que gerava o processo de dor referida e a tolerância máxima a palpação nos pontos estabelecidos. Os resultados obtidos foram que todos os $P G$ ativos produziram DR, enquanto para os PG latentes $46,8 \%$ dos casos apresentaram dor referida. 
Nos PA ativos, a pressão no ponto B causou dor referida em $100 \%$ dos casos, enquanto na faixa de músculo normal, em apenas $23 \%$. Para os PG latentes, $36 \%$ tiveram DR quando palpados em B e $23 \%$ quando palpados em C. Este achado é muito interessante e importante, pois elucida a necessidade de uma correta localização dos PG para o correto tratamento do mesmo, já que áreas normais também produziram DR. Esta produção de DR em áreas normais através de palpação também foi mostrada por Scudds ${ }^{32}$ em que ele obteve o processo de DR através de aplicação de pressão em pessoas que não apresentavam queixa de dor. ${ }^{11}$

Outras considerações têm que ser feitas em relação as variáveis que podem interferir na eficácia de medição de um algômetro. ${ }^{2,5,11,12,15,16,21,24} \mathrm{~A}$ taxa de aplicação de força, o tamanho da ponta ativa do aparelho e o grau de contração do músculo examinado podem apresentar interferências que modifiquem a leitura do LDP quando utilizamos aparelhos semelhantes ao algômetro.,5,6,21 Jaegger e Reeves ${ }^{15}$ em 1985 utilizaram um algômetro para determinar se havia diferença na tolerância a palpação de $P G$ antes e após a terapia com "spray" e alongamento. Verificaram que o algômetro foi capaz de detectar menores valores após tratamento com "spray" e alongamento dos músculos afetados havendo diferenças estatisticamente significante entre os valores comparados. Depois, Reeves, Jaeger e Graf-Radford ${ }^{29}$ demonstraram que o algômetro foi um aparelho que demonstrou capacidade e reprodutibilidade na mensuração da sensibilidade dos PG. 
Jensen ${ }^{16}$ no ano de 1986 propôs um novo tipo de algômetro, avaliando a eficácia deste aparelho na região temporal. A ponta ativa deste algômetro possuía uma área de $0.5 \mathrm{~cm}^{2}$, segundo o autor área esta menor que a polpa de dedo indicador. Apesar da variação inter e intra-individual, sempre se obteve uma significante correlação positiva entre as medições. Fisher ${ }^{5}$, McMillan e Blasberg ${ }^{21}$ utilizaram um algômetro para diagnosticar e avaliar a evolução do tratamento dos PG, enquanto Delaney e Mckee $^{3}$ utilizaram este aparelho para medir a concordância intra e inter-examinadores. Os aparelhos possuíam a ponta ativa com $1 \mathrm{~cm}^{2}$ de área, o que segundo os autores é suficientemente adequada para utilização em locais com sensibilidade alterada, como se ria o caso dos PG. O aparelho utilizado em nosso estudo possui uma ponta com uma área de aproximadamente $1 \mathrm{~cm}^{2}$, o que segundo Mense e SImons ${ }^{24}$, seria uma área ideal.

Outro fator a ser considerado é a velocidade de aplicação da força na área requerida. Praticamente todos os autores relatam a necessidade de se ter uma taxa de aplicação constante e que não seja muito rápida nem muito lenta. Jaegger e Reeves ${ }^{15}$; Fisher ${ }^{5}$; Delaney e McKee $^{3}$ e Jensen ${ }^{16}$ utilizaram uma pressão de 1kg/s. McMillan e Blasberg ${ }^{21}$ utilizaram uma taxa de aplicação de força equivalente a $0,5 \mathrm{Kg} / \mathrm{s}$ e em todos os trabalhos a ponta do algômetro foi posicionada perpendicularmente a pele nos locais a serem analisados. Após treinamento, a taxa aplicação de força que foi executada em nosso estudo foi de $1 \mathrm{~kg} / \mathrm{s}^{3,5,15,24}$ 
Em relação aos músculos a serem palpados, quando temos o músculo apoiado em uma estrutura rígida, como os músculos masséter e temporal, podemos palpá-los somente com um dedo ou com a ponta de algum aparelho. A presença de um anteparo possibilita que esta ponta possa exercer de forma adequada à pressão necessária para avaliar o LDP do músculo ou de um PG. Quando não há uma estrutura rígida abaixo dos músculos, como os ossos, não temos condições ideais de aplicar pressão digital puntiforme ou de aplicar pressão com um algômetro, pois a falta de um anteparo pode levar a um cedimento muscular e conseqüente imprecisão na leitura dos valores obtidos. Para os músculos esternocleidomastóideo ou trapézio que se encaixam na descrição acima, o exame de palpação não pode ser puntiforme, tendo então de ser executado através de pinçamento manual, como já mostrado em seção anterior. Este tipo de exame impossibilita que consigamos uma medição adequada da quantidade de pressão exercida e, conseqüentemente, quantificar a pressão necessária para causar dor referida e o LDP nestes músculos, embora o tempo de palpação necessário e o padrão de dor referida fosse perfeitamente viáveis de serem obtidos. 22,24,42,43,44,45

Os valores obtidos para o LDP em pacientes com dor miofascial em nosso estudo de $1,55 \mathrm{Kg}$ estão em parte de acordo com a literatura ${ }^{5}$. Há alguns autores que obtiveram valores maiores, porém as áreas examinadas não foram as mesmas. ${ }^{11}$ Langermark ${ }^{20}$ obteve para pacientes com dor crônica valor de $163 \mathrm{Kpa}$, sendo equivalente a 3,63 Kg. Apesar de não ter trabalhado 
especificamente com pacientes com dor miofascial, o autor afirma que, nestes indivíduos, o LDP é menor que em indivíduos assintomáticos, o que condiz com nossos achados. Em 1996, Honge col. ${ }^{11}$ realizaram palpação muscular em músculos com PG ativo e PG latente. Os valores para os PG latentes foram maiores e estatisticamente significantes do que os PG ativos, sendo os valores médios de $3.23 \mathrm{Kg}$ e $2.46 \mathrm{Kg}$, respectivamente. Também avaliaram a diferença entre o LDP e a pressão que causava dor referida. Para o grupo latente, a pressão para causar dor referida foi estatisticamente maior do que o LDP. Para o grupo com PG ativos, a diferença não foi estatisticamente significante, sendo os valores do LDP 2,46Kg e da pressão que causou dor referida de $2,73 \mathrm{Kg}$ em média. Este achado indica que ao ter-se um PG ativo e durante a palpação atingirmos o LDP não necessitamos aumentar a pressão para causar DR, enquanto que quando temos PG latentes, há a necessidade de se aumentar significantemente àpressão para obtermos DR. As áreas adjacentes na banda muscular tensa em que se encontram os $\mathrm{PG}$, tanto ativos quanto latentes, também podem ser capazes de produzir dor referida, porém tanto para o LDP ou pressão necessária para desencadear o processo de DR são mais altos e estatisticamente diferentes quando os PG são diretamente estimulados. ${ }^{11}$

Wright $^{48}$, em 2000, publicou um estudo no qual ele avaliou pacientes com dor miofascial nos músculos citados. Em sua revisão de literatura, citou que a pressão exercida deve ser aquela que provoca a isquemia da ponta do dedo, o que estima ser 3 a $4 \mathrm{Kg} / \mathrm{cm}^{2}$. Devido àdificuldade da quantificação e 
padronização da pressão exercida nos músculos, a utilização de um algômetro é valida para a medição quantitativa da pressão exercida. Estas diferenças existentes entre os resultados obtidos na literatura e os obtidos em nosso estudo podem ser devido a diferenças dos grupos musculares palpados. Outros fatores que pode influir no resultado é a falta de estudos que analisem especificamente o LDP em pontos gatilho, tendo que muitas vezes tentarmos comparar os valores obtidos em PG com outros tipos de pacientes, como os pacientes que portadores de fibromialgia. ${ }^{24,48}$

Tabela 6.1 - Média do LDP em pacientes portadores de dor miofascial.

\begin{tabular}{|c|c|}
\hline Autores & Pressão em KG \\
\hline Jaeger e Reeves & 2,8 \\
\hline Reeves et al. & 2,87 \\
\hline Goulet et al. & 1,8 \\
\hline McMillan et al. & 0,7 \\
\hline Hong et al & 2,46 \\
\hline
\end{tabular}

Quando comparamos os valores obtidos entre o exame de palpação no grupo $\mathrm{A}$ (sintomáticos) e $\mathrm{B}$ (assintomáticos), notamos que a média obtida no grupo A foi $1,55 \mathrm{Kg} / \mathrm{cm}^{2}(\mathrm{dp}=0,243859)$. e $3,84 \mathrm{Kg} / \mathrm{cm}^{2}(\mathrm{dp}=0,9044)$ para o 
grupo B. O valor para B está em acordo com valores obtidos em outros estudos, ${ }^{5,11,14}$ o que significa que, independentemente do tipo de algômetro utilizado, quando o operador é treinado para a realização do exame, os valores obtidos são confiáveis. ${ }^{3,4,16,17}$ Para o grupo A. Apenas alguns valores estão próximos aos obtidos por nós, as diferenças podem ser devido as regiões estudadas serem diferentes. ${ }^{3,4,5,11,14,16,17}$ Quando comparamos os valores entre os dois grupos aplicando o teste " $\mathrm{t}$ " de Student, verificamos que existe diferença estatística significante entre os dois grupos, sendo os valores do grupo $A$ significantemente menores que os obtidos para o grupo B.

Os achados de Hong e col. ${ }^{11}$ podem suportar o conceito formulado por Travel ${ }^{\beta 9}$ que existem três diferentes graus de irritabilidade do PG: altamente ativo pode causar dor referida espontaneamente com o músculo em descanso; moderadamente irritável que causa DR quando submetido a um estresse ou posição não ideal e PG latente, que causa DR somente quando este é fortemente comprimido. Hong e col. ${ }^{11}$ ainda afirmaram que a alta irritabilidade e conseqüente diminuição do LDP de um PG é devido a um aumento da sensitização de estruturas receptoras periféricas. Devido a este acontecimento, os neurônios sensoriais espinais recebem estímulos mais intensos dos receptores periféricos do que em situações normais, sendo também que este estímulo periférico pode atingir outros neurônios e assim causar dor referida em outros lugares periféricos. Por isto, $\mathrm{m}$ os $\mathrm{PG}$ ativos produzem DR mais facilmente do que os latentes. ${ }^{11,12}$ 
O tempo que deve ser mantida a pressão no PG para que cause DR também é um tópico que não tem muito suporte na literatura. Grande parte dos estudos que avaliam a quantidade de pressão necessária para o surgimento da DR não se importam com o tempo de palpação necessário, pois este não é o objetivo principal dos estudos. ${ }^{5,6,8,11}$ Travell e Simons ${ }^{39}$ em 1983 dizem que o tempo necessário de manutenção da pressão em PG ativos para que hajaa manifestação de DR é entre 10 e 15 segundos.

Os resultados obtidos neste estudo através da verificação do tempo necessário de manutenção da pressão em PG, para que houvesse a manifestação do processo de DR, foram menores que o tempo citado por Travell e Simons. ${ }^{39} \mathrm{O}$ tempo médio que obtivemos foi de 7,29 segundos, variando entre 2 e 16 segundos ( $d p=2,77$ ). Estes valores estão mais próximos do tempo proposto por Wrigth em $2000^{48}$. O autor ponderou que normalmente há um tempo entre o início da pressão e a manifestação da DR, sendo que ocasionalmente pode levar mais de 10 segundos. A partir desta afirmação pode-se observar que o autor não fala sobre um tempo determinado, e sim sobre um período de tempo. Diferentemente de Travell e Simons ${ }^{39}$, Wrigth $^{48}$ diz que tempos inferiores a 10 segundos são registrados com mais freqüência, o que condiz com a média de tempo obtida e também com a distribuição dos valores de tempo próximos à média, como pode ser observado na figura 5.1 da página 38. Jaegger ${ }^{15}$ que em um artigo clássico, sobre dores miofasciais que acometem a região de cabeça e pescoço, afrmou que a DR 
pode ser elucidada aplicando uma pressão firme no PG e mantendo a mesma por um período que varia de 6 a 20 segundos. Este intervalo é semelhante ao intervalo de tempo por nós obtido, sendo que em nossa amostra foi de 2 a 16 segundos.

Não houve diferenças estatísticas significantes entre os músculos palpados em função de existir semelhança estrutural dos PG, sendo que o mais importante é o grau de irritabilidade destes pontos e, conseqüentemente, a quantidade de pressão aplicada sobre eles. Entretanto, nenhum estudo tentou verificar estas diferenças.

Não é de nossa pretensão ditar um tempo determinado de palpação que possa provocar o processo de DR. Seria insana esta determinação, pois a sensibilidade local pode variar de indivíduo para indivíduo ou em uma mesma pessoa. Esta variação que pode ocorrer é inerente às características do próprio PG, devido a fatores como sensibilidade do mesmo, se ele está ativo ou latente ou se o músculo se manteve contraído por muito tempo.11,12,24,13 Hoheisel e col. ${ }^{10}$ demonstraram que existe um tempo entre a formação de novos campos receptivos e o surgimento da DR. O que seria mais sensato é a determinação de um intervalo de tempo, sem que haja valores fixos nas extremidades deste intervalo, pois vimos que estes valores extremos podem também variar de amostra para amostra. O que é importante, ou melhor, interessante saber é que na maioria dos casos o tempo necessário de manutenção da pressão no PG 
para causar DR é por volta de 7 segundos, mais uma vez alertando para que $\circ$ profissional não tome este valor com um fator determinante.

Contrariamente ao fato do tempo de manutenção de pressão não ser um fato descrito intensamente na literatura, o padrão de dor referida é extensamente relatado, principalmente por Janet Travel$\left.\right|^{\beta 8}$. Em 1960, a autora publicou um dos artigos pioneiros em relaçãoà área de manifestação de dor referida causa pelos PG. Para facilitar a leitura de maneira que não fique repetitiva e, conseqüentemente monótona, as áreas de manifestação de DR e seus respectivos campos de origem serão descritos posteriormente em na tabela 6.2. Jaeger ${ }^{15}$ também descreveu as áreas que ela obteve ao examinar os PG (ver tabela 6.2). Fricton e col. ${ }^{6}$ em 1985 avaliou 164 pacientes portadores de dor miofascial. Através desta avaliação, os autores verificaram a existência de DR nas estruturas orofaciais. Os resultados estão na tabela 6.2. Reeh e EIDeeb ${ }^{28}$ mostraram um caso onde houve a extirpação de órgão pulpar devido a DR manifestada na região do $1^{\circ}$ molar inferior esquerdo. A fonte da dor era um PG localizado no músculo masséter. Konzelman, Herman e Comer ${ }^{19}$ também relataram casos clínicos em que a região de manifestação da DR foi os dentes. Segundo os autores, os PG não causam somente o processo de DR para a região alveolar, mas também aumento na sensibilidade a percussão e sensibilidade térmica, o que pode causar nos mais desavisados um diagnóstico errôneo de dor de origem odontológica. ${ }^{26}$ 
Saxen $^{31}$ e Wright ${ }^{48}$ também alertaram para os processos de DR que podem ocorrer nos dentes, sendo que a fonte não seria estas estruturas e sim músculos como o masseter, digástrico ou temporal.

Tabela 6.2 - Áreas de dor referida segundo Travel| ${ }^{39}$; Travell, Simons ${ }^{42,43,44,45}$, Jaeger ${ }^{15}$; Fricton et al. ${ }^{6}$; Reeh, EIDeeb ${ }^{29}$; Saxen $^{31}$; Wright. ${ }^{48}$ * Cruzou a linha média.

\begin{tabular}{|c|c|c|}
\hline Músculos & Porção Muscular & Áreas de DR \\
\hline Trapézio & Superior e Inferior & $\begin{array}{l}\text { Aspecto posterolateral do } \\
\text { pescoço, processo mastóide, } \\
\text { têmpora, ângulo da } \\
\text { mandíbula, occipital }\end{array}$ \\
\hline Esternocleidomastóideo & $\begin{array}{l}\text { Divisão esternal e } \\
\text { clavicular }\end{array}$ & $\begin{array}{l}\text { Bochecha, maxila, região } \\
\text { supraorbital, occipital, área } \\
\text { frontal* }{ }^{*} \text { dentro do ouvido e } \\
\text { processo mastóideo. }\end{array}$ \\
\hline Masséter & Superficial e profundo & $\begin{array}{c}\text { Molares superiores, molares } \\
\text { inferiores, processo alveolar, } \\
\text { gengiva, região supra-orbital, } \\
\text { ouvido e ATM }\end{array}$ \\
\hline Temporal & $\begin{array}{l}\text { Anterior, médio e } \\
\text { posterior }\end{array}$ & $\begin{array}{c}\text { Dentes superiores, } \\
\text { sobrancelha, atrás do olho, } \\
\text { aspecto superior, anterior e } \\
\text { posterior da cabeça }\end{array}$ \\
\hline
\end{tabular}


Os resultados obtidos pela avaliação dos pacientes em nosso estudo, verificou o seguinte padrão de DR:

1. Masséter: Ouvido, maxila, ATM, processo alveolar da maxila, processo alveolar mandibular, têmpora.

2. Temporal: Região frontal, aspecto lateral da cabeça, esternocleidomastóideo, masseter.

3. Esternocleidomastóideo: maxila, frontal ${ }^{\star}$, temporal, processo mastóideo, ATM.

4. Trapézio: Processo mastóideo, ângulo da mandíbula, temporal e occipital.

Os resultados obtidos conferem com os padrões descritos por Travell ${ }^{39}$, Travell e Simons ${ }^{42,43,44,45}$, Reeh e EIDeeb ${ }^{29}$, Saxen $^{31}$, Fricton ${ }^{5}$, Wright ${ }^{48}$ e Jaeger ${ }^{15}$. Existem algumas diferenças entre os resultados apresentados e os presentes na literatura. Uma possível explicação para este fato, é que os pacientes podem não ter apontado ou descrito corretamente a região acometida pelo processo de DR. Muitos destes pacientes tinham dor generalizada, o que pode ter causado esta confusão. Um aspecto importante no reconhecimento da área de referência do processo doloroso, é que o paciente não esteja ciente de onde é esta área ou então que o profissional não diga para o paciente aonde ele pode sentir DR. Esta afirmação é fruto dos resultados obtidos por Branch, Carlson e Okeson ${ }^{1}$, que realizaram um estudo em que eles demonstraram que instruções que elucidem as áreas de DR antes do exame clínico, aumentam o 
número de casos de DR. Era, então, perguntado ao paciente em que local ele sentiu a dor referida, pedindo para que o mesmo falasse ou apontasse a região. É importante que o paciente em questão não seja influenciado pelo profissional, pois se mostrou que quando os pacientes são cientes de que vai haver um processo de dor referida e aonde esta dor irá acontecer, eles podem induzir resposta, gerando um alto grau de respostas falso-positivo. ${ }^{1}$

É de suma importância que o cirurgião-dentista saiba da existência destes processos de DR ativados por PG, para que não haja confusão e diagnóstico incorreto, acarretando assim em uma terapêutica não adequada e conseqüente manutenção do processo doloroso e PG, o que causa danos físicos, psicológicos e financeiros aos portadores de dor miofascial. 
Conclusões 


\section{7 - Conclusões}

Em virtude dos objetivos propostos e resultados conseguidos e analisados, pode-se concluir que:

1. O grupo de pacientes com dor miofascial possui menor LDP que indivíduos assintomáticos, sendo esta diferença estatisticamente significante.

2. O LDP nos $P G$ que causou $D R$ foi de $1,57 \mathrm{Kg} / \mathrm{cm}^{2}$.

3. O LDP em indivíduos assintomáticos foi de $3,84 \mathrm{Kg} / \mathrm{cm}^{2}$

4. A média do tempo de manutenção da pressão nos PG necessária para a manifestação de DR foi de aproximadamente 7 segundos.

5. O intervalo do tempo de manutenção da pressão nos PG variou de 2 a 16 segundos.

6. O padrão de DR apresentado foi semelhante ao proposto pela literatura, sendo, na maioria das vezes, no lado ipsilateral. 
Anexos 


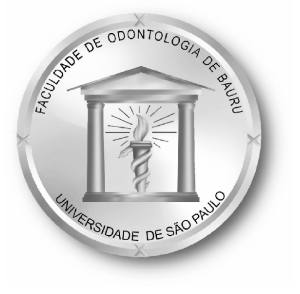

\author{
Universidade de São Paulo \\ Faculdade de Odontologia de Bauru \\ Al. Dr. Octávio Pinheiro Brisolla, 9-75 - Bauru-SP - CEP 17012-901 - \\ C.P. 73 \\ PABX (0XX14)235-8000 - FAX (0XX14)223-4679
}

\title{
Carta de informação ao paciente
}

A Faculdade de Odontologia de Bauru, através do mestrando Renato Oliveira Ferreira da Silva e sob a orientação do Prof. Dr. Paulo César Rodrigues Conti, realiza essa pesquisa com o intuito de melhorar e traçar parâmetros quanto ao tempo de pressão e pressão necessária em um dos exames diagnósticos mais importantes para a abordagem das Disfunções Têmporomandibulares (dor na articulação da mandíbula e/ou dos músculos da face, podendo ou não acompanhar dor de cabeça), especialmente os pacientes portadores de dor miofascial. Trata-se do exame de palpação, que consiste na execução de uma pressão com o(s) dedo(s) em determinadas áreas da face e do pescoço para, juntamente com a anamnese e o exame clínico, se chegar a um diagnóstico. Não se sabe com precisão o quanto de pressão deve ser exercida e por quanto tempo ela deve ser mantida para desencadear o processo de dor referida, por isso o interesse para a realização dessa pesquisa.

Será utilizado um aparelho capaz de medir pressão (algômetro), possuindo uma ponta circular que fica em contato com determinadas áreas da face do paciente. A forma dessa ponta não machuca a face do paciente. Assim sendo, com o algômetro será efetuado o exame de palpação até o paciente relatar desconforto e o valor registrado será anotado, bem como o tempo que leva para desencadear o processo de dor referida. Nos casos dos indivíduos que apresentam alguma sintomatologia dolorosa facial (DTM), essa dor pode ser levemente exacerbada após o exame. Vale lembrar que qualquer paciente que procura tratamento para DTM e apresenta dor miofascial é obrigatoriamente submetido a esse exame e, portanto, não será um incômodo a mais participar dessa pesquisa. A participação nessa pesquisa não proporciona qualquer tipo de risco ao paciente.

Com a realização dessa pesquisa, pode-se melhorar o grau de confiabilidade do exame de palpação, aumentando assim a segurança ao se dar um diagnóstico e ao se planejar um tratamento.

Após a realização do exame e coleta dos dados, TODOS os pacientes receberão tratamento na clínica de Dor e Disfunção Temporomandibular dessa faculdade. 
Vale salientar que, agora ou durante o tratamento, o paciente tem a total liberdade para opinar, perguntar a respeito dos benefícios, riscos e procedimentos e até mesmo para desistir de participar dessa pesquisa, sem qualquer prejuízo à continuidade do tratamento nessa instituição.

A identidade de cada indivíduo será mantida em absoluto sigilo durante e após a realização dessa pesquisa.

O paciente não terá nenhum custo durante a realização dessa pesquisa.

Prof. Dr. Paulo César R. Conti

Orientador
Renato Oliveira Ferreira da SIlva

Mestrando em Reabilitação Oral 


\section{Universidade de São Paulo Faculdade de Odontologia de Bauru}

Pesquisa: Quantidade de pressão, tempo de manutenção de pressão e padrão de dor referida em pacientes portadores de Dor Miofascial Orientador: Paulo César Rodrigues Conti Orientado e examinador: Renato Oliveira Ferreira da Silva

\section{Ficha de Exame}

Data do exame:

Grupo: Sintomático ( ) Assintomático ( )

Nome:

Idade: Gênero:

Endereço:

Cidade: Telefone:

Exame

\begin{tabular}{llll}
\hline Músculo & $\frac{\text { Tempo de }}{\text { Afetado }}$ & $\underline{\text { Quantidade de }}$ & Local de DR \\
\hline
\end{tabular}


REFERÊNCIAS BIBLIOGRÁFICAS 


\section{REFERÊNCIAS BIBLIOGRÁFICAS}

1. BRANCH, M.A.; CARLSON, C.R.; OKESON, J.P. Influence of biased clinician statements on patient report referred pain. J. Orofac. Pain., v.14, n.2, p.120-7, 2000.

2. BENDTSEN, L. et al. Muscle palpation with controlled finger pressure: new equipment for the study of tender myofascial tissues. Pain., v.59, p.2359, 1994.

3. DELANEY, G.A.; MCKEE, A.C. Inter and intra-rater reliability of the pressure threshold meter in measurement of myofascial trigger point sensitivity. Am. J. Phys. Med. Rehabil,, v.72, n.3, p. 136-9, June, 1993.

4. DROBEK, W.; DE LAAT, A.; SCHOENAERS, J. Tactile threshold and pressure pain threshold during treatment of orofacial pain: an explorative study. Clin. Oral Invest., v.5, p.185-93, 2001.

5. FISCHER, A.A. Pressurethreshold measurement for diagnosis of miofascial pain and evaluation of treatment results. The Clinical J. Pain, v.2, n.4, p.207-14, 1987. 
6. FRICTON, J.R. et al Myofascial pain syndrome of the head and neck: A review of clinical characteristics of 164 patients. Oral Surg., v.60, n.6, December, p.615-23., 1985.

7. FRICTON, J.R. Myofascial pain syndrome. Advances in Pain Research Therapy., v.17, p.107-27, 1990.

8. GERWIN, R.D. et al. Interrater reliability in myofascial trigger point examination. Pain., v. 69, p.65-73, 1997.

9. GOULET, J.P.; et al. The reproducibility of muscle and joint tenderness detection methods and maximum mandibular movement measurement for the temporomandibular system. J. Orofac. Pain, v.12, n.1, p.17-26, 1998.

10. HOHEISEL, U. et al. Appearance of new receptive fields in rat dorsal horn neurons following noxious stimulation of skeletal muscle: a model for referral of muscle pain? Neurosc. Lett., v.153, p.9-12, 1993.

11. HONG, C.; et al. Pressure threshold for referred pain by compression on the trigger point and adjacent areas. J. Musculosk. Pain, v.4, n.3, p.61$79,1996$.

12. HONG, C.; Simons, D.G. Pathophysiologic and eletrophysiologic mechanisms of myofascial trigger points. Arc. Phys. Med. Rehabil., v.79, p.863-72, July, 1998.

13. ISSELÉE, H.; et al. Shot-term reproducibility of pressure pain thresholds in masséter and temporalis muscles of symptom-free subjects. Eur. J. Oral Sci., v.10, n.5, p.583-7, 1997. 
14. ISSELÉE, H.; et al. Short-term reproducibility of pressure pain thresholds in masticatory muscles measured with a new algometer. J. Orofac. Pain., v.12, n.3, p.203-9, 1998.

15. JAEGER, B.; REEVES, J.L. Quantification of changes in myofascial trigger point sensivity with the pressure algometer following passive stretch. Pain., v.27, p.203-10, 1986.

16. JENSEN, K.; et al. Pressure-pain threshold in human temporal region. Evaluation of a new pressure algometer. Pain., v.25, p.313-23, 1986.

17. JENSEN, R. et al. Cephalic muscle tenderness and pressure pain threshold in general population. Pain., v.48, p.197-203, 1992.

18. KEELE, K.D. Pain - sensitivity tests. Lancet., v.27, p.636-9, 1954.

19. KONZELMAN JR, J.L.; HERMAN, W.W.; COMER, R.W. Pseudo-dental pain and sensitivity to percussion. Gen.Dent., march-april, p. 156-8. 2001.

20. LANGEMARK, M. et al. Pressure pain thresholds and thermal nocioceptive thresholds in chronic tension-type headache. Pain., v.38, p.203-10, 1989.

21. MCMILLAN, A.S.; BLASBERG, B. Pain-Pressure threshold inpainful jaw muscles following trigger points injection. J.Orofac. Pain., v.8, n.4, p.384-90, 1994

22. MENSE, S.; S IMONS, D.G. Back ground and basic principles. In: . Muscle Pain. Understanding its nature, diagnosis, and treatment. Philadelphia, Lippincott Williams \& Wilkins, 2001. Cap.1, p.1-19. 
23. MENSE, S.; SIMONS, D.G. Pain referred from and to muscles. In: . Muscle Pain. Understanding its nature, diagnosis, and treatment. Philadelphia, Lippincott Williams \& Wilkins, 2001. Cap 4, p.84-98.

24. MENSE, S.; SIMONS, D.G. Myofascial pain caused by trigger points. In:_. Muscle Pain. Understanding its nature, diagnosis, and treatment. Philadelphia, Lippincott Williams \& Wilkins, 2001. Cap 5, p.205-88.

25. MERRIL, R.L. Orofacial pain mechanisms and their clinical application. Dent. Clin. Of North Am., v.41, n.2, p.167-88, April, 1997.

26. OKESON, J.P. Nonodontogenic toothache Dent.Clin. Of North Am. , v.41, n.2, p.367-83, April, 1997.

27. PALLA, S. Fourth world congress on myofascial pain. J. Orofac. Pain., v.12, n.4, p.312-4, 1998

28. REEH, E.S.; El-DEEB, M.E. Referred pain of muscular origin resembling endodontic involvement. Oral Surg. Oral Med. Oral Pathol., v.71, n.2, Feb., p.223-7, 1991.

29. REEVES, J.L.; JAEGER, B.; GRAF-RADFORD, S.B. Reliability of the new pressure algometer as a measure of myofascial trigger point sensitivity. Pain., v.24, p.313-21, 1986.

30. REID, K.I.; GRACELY, R.H.; DUBNER, R.A. The influence of time, facial side, and location on pain-pressure thresholds in chronic myogenous temporomandibular disorder. J. Orofac. Pain., v.8, n.3, p.258-65, 1994. 
31. SAXEN, M.A. Myofascial pain syndrome: characteristics, diagnosis, and treatment. J. Ind. Dent. Assoc., v.77, n.3, p.09-12, 1998.

32. SCUDDS, R.A. et al. The frequency of referred signs from muscle pressure in normal healthy subjects. J. Musculosk. Pain., v.3, supl.1, p.99, 1995.

33. SESSLE, B.J. Masticatory muscle disorders: Basic Science perspectives. In: SESSLE, B.J.; BRYANT, P.S.; DIONNE, R.A. Temporomandibular disorders and related pain conditions. Progress in pain research and Management. Seattle, IASP Press, 1995. V.4, cap.3, p.47-61.

34. SESSLE, B.J. The neural basis of temporomandibular joint and masticatory muscle pain. J.Orofac. Pain., v.13, n.4, p.238-45, 1999.

35. STHOLER, C.S. Clinical perspectives on masticatory and related muscle disorders. In: SESSLE, B.J.; BRYANT, P.S.; DIONNE, R.A. Temporomandibular disorders and related pain conditions. Progress in pain research and Management. Seattle, IASP Press, 1995. V.4, cap.1, p.3-31.

36. STHOLER, C.S. Muscle-Related temporomandibular disorders. J. Orofac.Pain., v.13, n.4, p.273-84, 1999.

37. SVENSSON, P.; GRAVEN-NIELSEN, T. Craniofacial muscle pain: review of mechanisms and clinical manifestations. J. Orofac. Pain., v.15, n.2, p. 117-45, 2001.

38. TRAVELL, J.G. Temporomandibular joint pain referred from muscles of the head and neck. J. Pros. Dent., v. 10, n.4, July-August, p.745-63., 1960 
39. TRAVELL, J.G.; SIMONS, D.G. Background and principles. In:

Myofascial pain and dysfunction. The trigger point Manual.

Baltimore, Williams \& Wilkins, 1983. Cap. 2, p. 5-44.

40. TRAVELL, J.G.; SIMONS, D.G. Apropos all muscles. In:

Myofascial pain and dysfunction. The trigger point Manual.

Baltimore, Williams \& Wilkins, 1983. Cap.3, p. 45-102.

41. TRAVELL, J.G.; SIMONS, D.G. Perpetuating factors. In:

Myofascial pain and dysfunction. The trigger point Manual.

Baltimore, Williams \& Wilkins, 1983. Cap.4, p. 103-64.

42. TRAVELL, J.G.; SIMONS, D.G. Head and neck pain and muscle guide introduction to masticatory muscles. In: Myofascial pain and

dysfunction. The trigger point Manual. Baltimore, Williams \& Wilkins, 1983. Cap.5, p. 165-82.

43. TRAVELL, J.G.; SIMONS, D.G. Trapezius muscle. The coat hanger In: Myofascial pain and dysfunction. The trigger point

Manual. Baltimore, Williams \& Wilkins, 1983. Cap.6, p. 183-201. 44. TRAVELL, J.G.; SIMONS, D.G. Sternocleidomastoid Muscle In:

Myofascial pain and dysfunction. The trigger point Manual.

Baltimore, Williams \&Wilkins, 1983. Cap.7, p. 202-18.

45. TRAVELL, J.G.; SIMONS, D.G. Masseter muscle. In:

Myofascial pain and dysfunction. The trigger point Manual.

Baltimore, Williams \& Wilkins, 1983. Cap.8, p. 219-35. 
46. TRAVELL, J.G.; SIMONS, D.G. Temporalis Muscle. In:

Myofascial pain and dysfunction. The trigger point Manual.

Baltimore, Williams \& Wilkins, 1983. Cap.9, p. 236-48.

47. WIDMER, C.G. Physical characteristics associated with temporomandibular disorders. In: SESSLE, B.J.; BRYANT, P.S.; DIONNE, R.A.

Temporomandibular disorders and related pain conditions.

Progress in pain research and Management. Seattle, IASP Press, 1995. V.4, cap.10, p.161-74.

48. WRIGHT, E.F. Referred craniofacial pain patterns in patients with temporomandibular disorder. J. Am. Dent. Assoc., v.131, n.9, p.130715, 2000. 


\section{$\underline{\text { ABSTRACT }}$}

The purposes of this study were: to determine the amount of pressure necessary to create painful response in patients with myofascial pain in head and neck when compared with a assintomatic control group; to determine one sustained pressure time that causes referred pain and to determine the referred pain pattern when the trigger points were stimulated. The group A was formed by 24 patients who had myofascial pain, and group B was composed by 20 myofascial pain free subjects. For both groups, examination was performed by only an experienced and trained professional. Group A had lower pressure pain threshold when compared with group B. $(p<0,01)$ The range of sustained pressure, was between 2 and 16 seconds, with an average of 7 seconds. The referred pain patterns was very similar to those described in literature. It was concluded that the pressure pain threshold in myofascial pain patients is lower than pressure pain threshold in non-patients. Also, the average time for sustained pressure to stimulate the referred pain is approximately 7 seconds and the referred pain pattern were similar to that described in dental end medical literature. 